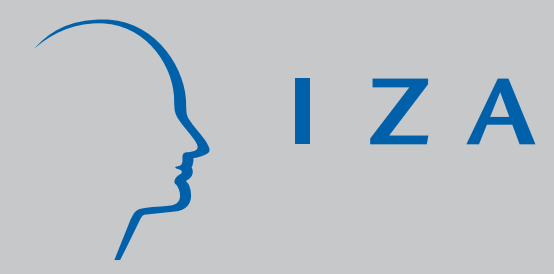

IZA DP No. 2652

Identification of Peer Effects through Social Networks

Yann Bramoullé

Habiba Dj ebbari

Bernard Fortin

March 2007 


\title{
Identification of Peer Effects through Social Networks
}

\author{
Yann Bramoullé \\ CIRPÉE, Université Laval
}

Habiba Djebbari

CIRPÉE, Université Laval

and IZA

Bernard Fortin

CIRPÉE, Université Laval

\section{Discussion Paper No. 2652 \\ March 2007}

\author{
IZA \\ P.O. Box 7240 \\ 53072 Bonn \\ Germany \\ Phone: +49-228-3894-0 \\ Fax: +49-228-3894-180 \\ E-mail: iza@iza.org
}

\begin{abstract}
Any opinions expressed here are those of the author(s) and not those of the institute. Research disseminated by IZA may include views on policy, but the institute itself takes no institutional policy positions.

The Institute for the Study of Labor (IZA) in Bonn is a local and virtual international research center and a place of communication between science, politics and business. IZA is an independent nonprofit company supported by Deutsche Post World Net. The center is associated with the University of Bonn and offers a stimulating research environment through its research networks, research support, and visitors and doctoral programs. IZA engages in (i) original and internationally competitive research in all fields of labor economics, (ii) development of policy concepts, and (iii) dissemination of research results and concepts to the interested public.
\end{abstract}

IZA Discussion Papers often represent preliminary work and are circulated to encourage discussion. Citation of such a paper should account for its provisional character. A revised version may be available directly from the author. 


\section{ABSTRACT \\ Identification of Peer Effects through Social Networks ${ }^{*}$}

We provide new results regarding the identification of peer effects. We consider an extended version of the linear-in-means model where each individual has his own specific reference group. Interactions are thus structured through a social network. We assume that correlated unobservables are either absent, or treated as fixed effects at the component level. In both cases, we provide easy-to-check necessary and sufficient conditions for identification. We show that endogenous and exogenous effects are generally identified under network interaction, although identification may fail for some particular structures. Monte Carlo simulations provide an analysis of the effects of some crucial characteristics of a network (i.e., density, intransitivity) on the estimates of social effects. Our approach generalizes a number of previous results due to Manski (1993), Moffitt (2001), and Lee (2006).

JEL Classification: D85, L14, Z13, C3

Keywords: peer effects, social networks, identification

Corresponding author:

Habiba Djebbari

Université Laval

Department of Economics

Pavillon DeSève - Room 2290

Québec (QC) G1K 7P4

Canada

E-mail: hdjebbari@ecn.ulaval.ca

\footnotetext{
* We are grateful to Oriana Bandiera, Charles Bellemare, Arianna Degan, Ron Laschever, Robert Moffitt, Imran Rasul, Jean-Marc Robin, Patrick Sevestre, Jose Scheinkman, and seminar participants at the University of Toronto, the Universite de Paris 1, the CREST, the European Summer Symposium in Economic Theory (2006), the 12th International Conference on Computing in Economics and Finance and the annual CIRPÉE Conference (2006) for many helpful comments.
} 


\section{Introduction}

One key challenge for the empirical literature on peer effects is to identify what drives the correlation between outcomes of individuals who interact together (see Blume and Durlauf (2005) and Soetevent (2006) for recent surveys). In a pioneer study, Manski (1993) distinguishes between endogenous effect, i.e., the influence of peer outcomes, exogenous (or contextual) effects, i.e., the influence of exogenous peer characteristics, and correlated effects, i.e., individuals in the same reference group tend to behave similarly because they are alike or face a common environment. Manski shows that two main identification problems arise in the context of a linear-in-means model. ${ }^{1}$ First, it is difficult to distinguish real social effects (endogenous + exogenous) from correlated effects. ${ }^{2}$ Second, even in the absence of correlated effects, simultaneity in behavior of interacting agents introduces a perfect collinearity between the expected mean outcome of the group and its mean characteristics. This 'reflection' problem hinders the identification of the endogenous effect from the exogenous effects. ${ }^{3}$

One basic assumption that is usually made in the linear-in-means model, as well as in most peer effects models, is that individuals interact in groups. This means that the population is partitioned in groups, and that individuals are affected by all others in their group and by none outside of it. This interaction pattern is very particular and is not likely to represent most forms of relationship between individuals. Indeed, there is increasing recognition among economists and social scientists in general of the role played by social networks in structuring interactions

\footnotetext{
${ }^{1}$ In the linear-in-means model, the outcome of each individual depends linearly on his own characteristics, on the mean outcome of his reference group and on its mean characteristics. Most papers on social interactions have considered the linear-in-means model since it is naturally related to the standard simultaneous linear model (Moffitt 2001). Notable exceptions are Brock and Durlauf (2001a, 2003) that exploit non-linearities emerging from discrete choice models to identify endogenous from exogenous effects under the assumption of no correlated effects, Krauth (2006) that extents Brock and Durlauf (2001a) to account for correlated effects, Glaeser, Sacerdote and Scheinkman (1996) that provide a non-parametric test of the existence of social interaction effects, and Fortin, Lacroix and Villeval (2006) that use a mixed discrete-continuous model with group-specific fixed effects. Brock and Durlauf (2001b) provide a careful analysis of identification in both linear-in-means and discrete choice models.

${ }^{2}$ Empirical studies have notably addressed this problem by exploiting data where individuals are randomly assigned to groups (removing any correlated effects), e.g., Sacerdote (2001) and Zimmerman (2003), by using instrumental variables, e.g., Evans, Oates and Schwab (1992) and Graham and Hahn (2005), or by assuming that correlated effects are time-invariant and estimating a group specific fixed effects model using panel data, e.g., Hanushek et al. (2003).

${ }^{3}$ Empirical studies have addressed this issue in many ways: for instance by assuming that only one type of social effect exists (endogenous or exogenous), e.g., Graham and Hahn (2005), by assuming that there exists an individual characteristic that affects outcome but which does not play the role of a contextual variable or more generally, by assuming the existence of an instrumental variable, e.g., Gaviria and Raphael (2001) and Hanushek et al. (2003). These assumptions are often $a d$ hoc and in any case cannot be tested when the model is exactly identified.
} 
among agents. A growing body of theoretical work explores how individual incentives give rise to networks and, in turn, can be shaped by them (e.g., see Jackson 2006). At the empirical level, a few recent studies exploit datasets possessing rich information on relationships between agents in order to provide cleaner evidence on social effects. ${ }^{4}$ Network datasets are especially valuable to determine the appropriate reference groups likely to influence an individual's behavior. It is thus natural to analyze the problem of identification under more general assumptions.

Our approach is inspired from the literature in spatial econometrics (e.g., see Anselin et al. 2004). We consider an extended version of the linear-in-means model where each individual has his own specific reference group, defined by the individuals whose mean outcome and characteristics influence his own outcome. Interactions are thus structured through a directed social network (e.g., Wasserman and Faust 1994). We show that relaxing the assumption of group interactions generally permits to separate endogenous and exogenous effects. Therefore, the second negative result of Manski (1993) is not robust to reference group heterogeneity. This result is important since distinguishing between both peer effects is necessary to evaluate the impact of policies on outcomes of networks with different structure. It also helps to detect which mechanism is at work within a network. ${ }^{5}$ More generally, inference on parameters with behavioral interpretation requires estimates of the structural form of the model.

Our main objective is to characterize the networks for which endogenous and exogenous effects are identifiable. We determine these structures both in the absence of correlated effects and when controlling for correlated effects in the form of component fixed effects. ${ }^{6}$ In both cases, we provide easy-to-check necessary and sufficient conditions for identification. When there are no correlated effects, we show that endogenous and exogenous effects are identified as soon as individuals do not interact in groups. ${ }^{7}$ Thus, even the slightest departure from a groupwise structure is sufficient to obtain identification. In many networks, identification originate from natural exclusion restrictions induced by the structure. For instance, identification is guaranteed if an individual has a friend's friend who is not his friend (i.e., the network has an intransitive

\footnotetext{
${ }^{4}$ Dercon and DeWeerdt (2005) study the network of risk-sharing relationships between households in a Tanzanian village. Conley and Udry (2005) look at how communication networks among farmers affect the adoption of a new technology. Goyal et al. (2006) analyze the network of coauthorships among economists. Calvó-Armengol, Patacchini and Zenou (2005) and Lin (2005) study the AddHealth dataset and friendship networks among adolescents.

${ }^{5}$ For instance, imitation and conformism in behavior can be eliminated when only exogenous effects are present.

${ }^{6} \mathrm{~A}$ component is a maximal set of individuals indirectly related to each other, see Section 3.

${ }^{7}$ We also show that they may be identified under group interactions, see our discussion on Lee (2004) below.
} 
triad). The intuition is that the characteristics of his friend's friend do not directly affect the individual's outcome but they affect it indirectly through their effects on his friend's outcome. This imposes an identifying restriction to the model.

When correlated effects are present at the component level, it is natural to take them out through a within transformation similar to the one used in panel data models. However many transformations can be used for this purpose. We focus on two of them: the local transformation which expresses the model in deviation from the mean equation of the individual's neighbors and the global transformation which expresses it in deviation from the individual's component. We show that the global transformation is the one which imposes less restrictive conditions to obtain identification. Whatever the transformation used, degrees of freedom are lost, and identification now fails on some networks, such as the star. We still find that endogenous and exogenous effects can be distinguished on most networks.

Our analysis admits as special cases several models studied in the literature, among which Manski (1993), Moffitt (2001) and Lee (2006). These authors analyze different versions of the standard model with group interactions. For our purposes, Manski's model has the same properties as one where the individual is included when computing the mean of the group. ${ }^{8}$ In this case, peer effects are not identified. In Moffitt's model, the individual is excluded from the mean and all groups have the same size. Peer effects are also not identified. In contrast, Lee's model considers interactions in groups with different sizes, and the individual is also excluded from the mean. He finds that variations in group sizes can yield identification. ${ }^{9}$ We show that these three results directly follow from our general conditions. Observe that Lee's result may have important empirical implications. Econometric analysis in existing studies that neglect these size effects may be misspecified. ${ }^{10}$ Conversely, prospects for identification with standard datasets may be better than usually thought.

Our paper advances the methodology of the empirical estimation of peer effects. We provide

\footnotetext{
${ }^{8}$ More precisely, Manski develops a linear-in-expectations model, where the individual's outcome depends on the outcome expectation of his group and social equilibrium is assumed. In the absence of correlated effects, the reduced form of this model is similar to that of a linear-in-means model, where a non-cooperative Nash equilibrium is assumed and where the individual is included when computing the mean.

${ }^{9}$ Identification could be weak if the group sizes are large. See the discussion in Lee (2004).

${ }^{10}$ For instance, in the sample of Sacerdote (2001), $53 \%$ of roommates are in double rooms, $44 \%$ are in triples, and $3 \%$ in quads. The author assumes that the individual is excluded from the mean and that reduced-form coefficients do not depend on the number of roommates. This may only be true under the assumption of no endogenous effects.
} 
a theoretical foundation behind a few recent attempts at identifying and estimating social effects (Laschever 2005, and Lin 2005). Laschever (2005) applies a model of social interactions with multiple reference groups to the likelihood of post-war employment of World War I veterans. As shown in this paper, a multiple reference group structure is only one of many structures of interaction for which social effects can be identified. ${ }^{11}$ Lin (2005) uses detailed data on friendship links to estimate peers' influence on students' outcomes. He can obtain separate estimates for endogenous and exogenous effects only because the friendship networks in his dataset satisfy our general identification conditions.

While theoretically identified, a social interaction model can suffer from weak identification in practice. Our paper also provides Monte Carlo simulations which analyze the effects of important characteristics of a network, such as its density (that is, the proportion of actual over potential links) and its level of intransitivity, on the quality of estimates of peer effects.

The rest of the paper is organized as follows. Section 2 introduces the extended linear-inmeans model, and presents our basic identification results. Section 3 addresses correlated effects in the form of component fixed effects. Section 4 present our Monte Carlo simulations. A brief discussion concludes.

\section{Social Effects and Social Networks}

\subsection{The Structural Model}

Our model is an extension of the standard linear-in-means social interactions model in which we allow for individual-specific reference groups. We follow the formulation of Moffitt (2001). Vectors are denoted with bold letters. Suppose we have a set $N$ of individuals $i(i \in\{1,2, \ldots, n\})$. Let $y_{i}$ be the outcome of interest for individual $i$. Let $x_{i}$ be a socioeconomic characteristic of $i$. For simplicity, we present the model with a unique characteristic. Results hold with any number of them (see Appendices for more details). Our main new assumption is as follows. Each individual $i$ may have a specific reference group $N_{i} \subset N$ of size $n_{i}$. This reference group (known by the modeler) contains all individuals whose outcome or characteristics may affect $i$ 's outcome. Except where otherwise specified, we assume that individual $i$ is excluded from his reference group, that

\footnotetext{
${ }^{11}$ While Laschever's model is somewhat different from ours, the reason for identification is similar.
} 
is, $i \notin N_{i}$. This corresponds to the usual empirical formulation (e.g., Sacerdote 2001, Hanushek et al. 2003, Soetevent and Kooreman 2005). An individual is isolated if his reference group is empty. ${ }^{12}$ We assume that not all individuals are isolated. The collection of individual-specific reference groups defines a directed network between individuals.

Our results are consistent with two types of observations. First, they hold if we observe an i.i.d. sample of size $L$ from a population of networks with a fixed and known structure. Alternatively, they hold if we observe an i.i.d. sample $L$ from a population of networks with a stochastic but strictly exogenous structure. For notational simplicity, our results are presented for a fixed network; they can be easily adapted to the latter case (see discussion below). Also, to focus on the population model, we omit for the moment the network observation index $l$, $(l=1, \ldots, L)$.

We do not change any other assumption of the standard model. Especially, we assume that the individual outcome may be affected by the individual characteristics, by the mean outcome in the individual's reference group (endogenous social effect), and by the mean characteristics in the individual's reference group (exogenous social effect). Formally, the structural model is given by:

$$
y_{i}=\alpha_{0}+\alpha_{1} x_{i}+\alpha_{2} \frac{\sum_{j \in N_{i}} y_{j}}{n_{i}}+\alpha_{3} \frac{\sum_{j \in N_{i}} x_{j}}{n_{i}}+\epsilon_{i}
$$

where $\alpha_{2}$ captures endogenous effects and $\alpha_{3}$ exogenous effects. It is standard to require that $\left|\alpha_{2}\right|<1$. Except for this restriction, our model does not impose any other constraints on the $\alpha$ 's. The error term $\epsilon_{i}$ reflects unobservable (to the modeler) characteristics associated with $i$. In this section, we assume strict exogeneity of the error terms, that is $E\left(\epsilon_{i} \mid \mathbf{x}\right)=0$ where $\mathbf{x}$ is the vector $\left(x_{i}\right)$. Thus we assume no correlated effects. This assumption is relaxed in the next section. We make no further assumption on the error terms. Especially, they are not necessarily i.i.d. or normally distributed. ${ }^{13}$ Thus our model is semiparametric, or "distribution-free".

We finally write the structural model using condensed notations. Thus, $\mathbf{y}$ is the vector $\left(y_{i}\right)$, while $\mathbf{1}$ is the vector of ones. Let $\mathbf{i}$ denote the identity matrix. Introduce the interaction matrix

\footnotetext{
${ }^{12}$ While an isolated individual is not affected by others, he may still affect others.

${ }^{13}$ This structural model can be derived from a choice-theoretic approach where each individual $i$ chooses his outcome in order to maximize a quadratic utility function depending on his outcome and on his reference group's mean expected outcome and mean characteristics. This approach also assumes that social interactions have reached a noncooperative (Nash) equilibrium at which expected outcomes are realized.
} 
g as follows: $g_{i j}=1 / n_{i}$ if $j \in N_{i}$, and 0 otherwise. ${ }^{14}$ Equation (1) becomes:

$$
\mathbf{y}=\alpha_{0} \mathbf{1}+\alpha_{1} \mathbf{x}+\alpha_{2} \mathbf{g y}+\alpha_{3} \mathbf{g} \mathbf{x}+\boldsymbol{\epsilon},
$$

with $E(\boldsymbol{\epsilon} \mid \mathbf{x})=\mathbf{0}$ and $E\left(\boldsymbol{\epsilon} \boldsymbol{\epsilon}^{\prime} \mid \mathbf{x}\right)=\boldsymbol{\Sigma}$, where $\boldsymbol{\Sigma}$ is symmetric and positive definite but unrestricted otherwise. Therefore $\boldsymbol{\Sigma}$ contains no identifying information. We assume throughout that the expected outer product matrix of $(\mathbf{1}, \mathbf{x})$ has full rank. This formulation makes clear that the structural theoretical model is composed of a system of linear simultaneous equations with crossand within-equation parameter restrictions. Indeed, the $\alpha$ 's are the same across equations and the coefficients $\alpha_{2}$ and $\alpha_{3}$ associated with the individual $i$ ' reference group are the same within any equation) . Observe also that the systematic part of (2) is similar to that of a spatial autoregressive (SAR) model (e.g., see Cliff and Ord 1981) extended to allow for exogenous effects. It is also an extension of Lee (2006)'s model since, in its general version, it does not impose that individuals interact in groups. ${ }^{15}$

\subsection{Reduced Form and Identification}

We now write the restricted reduced form of model (2). Since $\mathbf{i}-\alpha_{2} \mathbf{g}$ is invertible, ${ }^{16}$ it can be written as:

$$
\mathbf{y}=\alpha_{0}\left(\mathbf{i}-\alpha_{2} \mathbf{g}\right)^{-\mathbf{1}} \mathbf{1}+\left(\mathbf{i}-\alpha_{2} \mathbf{g}\right)^{-1}\left(\alpha_{1} \mathbf{i}+\alpha_{3} \mathbf{g}\right) \mathbf{x}+\left(\mathbf{i}-\alpha_{2} \mathbf{g}\right)^{-1} \boldsymbol{\epsilon},
$$

where the intercept is simply $\alpha_{0} /\left(1-\alpha_{2}\right)$ if the individual is not isolated, and $\alpha_{0}$ otherwise and where the variance-covariance matrix of the errors terms $\left(\mathbf{i}-\alpha_{2} \mathbf{g}\right)^{-1} \boldsymbol{\epsilon}$ is given by $\boldsymbol{\Omega}=\left(\mathbf{i}-\alpha_{2} \mathbf{g}\right)^{-1}$ $\boldsymbol{\Sigma}\left(\mathbf{i}-\alpha_{2} \mathbf{g}\right)^{\prime-1}$.

We say that social effects are identified if and only if the set of structural parameters $\left(\alpha_{0}, \alpha_{1}, \alpha_{2}, \alpha_{3}\right)$ can be uniquely recovered from the restricted reduced form parameters in (3) (injective relationship). ${ }^{17}$ This means that it is impossible to find different sets of values for the structural para-

\footnotetext{
${ }^{14}$ More generally, $g_{i j}$ could capture the strength of the interaction between $i$ and $j$, and decrease with social, or geographic, distance. Some of our results hold for arbitrary g, others for matrices that are row-normalized (see discussion below).

${ }^{15}$ Lee (2006)'s model allows for group fixed effects, which we ignore here. In section 3, we introduce component fixed effects in our model.

${ }^{16}$ This is the case since $\left|\alpha_{2}\right|<1$. For a demonstration, see Case (1991), footnote 5 .

${ }^{17}$ Since $\boldsymbol{\Sigma}=\left(\mathbf{i}-\boldsymbol{\alpha}_{2} g\right) \boldsymbol{\Omega}\left(\mathbf{i}-\boldsymbol{\alpha}_{2} g\right)^{\prime}$, it can be uniquely recovered from $\boldsymbol{\Omega}$ and $\alpha_{2}$.
} 
meters that are observationally equivalent. ${ }^{18}$ As usual, our identification results are asymptotic in nature (see Manski 1995). They characterize when social effects can, or cannot, be disentangled if we are not limited in the number of observations we can obtain.

It will be useful in the following to use a series expansion of (3). Since $\left(\mathbf{i}-\alpha_{2} \mathbf{g}\right)^{-1}=$ $\sum_{k=0}^{\infty}\left(\alpha_{2}\right)^{k} \mathbf{g}^{k}$ and assuming no isolated individuals, one has:

$$
\mathbf{y}=\alpha_{0} /\left(1-\alpha_{2}\right) \mathbf{1}+\alpha_{1} \mathbf{x}+\left(\alpha_{1} \alpha_{2}+\alpha_{3}\right) \sum_{k=0}^{\infty}\left(\alpha_{2}\right)^{k} \mathbf{g}^{k+1} \mathbf{x}+\sum_{k=0}^{\infty}\left(\alpha_{2}\right)^{k} \mathbf{g}^{k} \boldsymbol{\epsilon}
$$

Moreover, from (4), the expected mean outcomes of reference groups conditional on $\mathbf{x}$ can be written as:

$$
E(\mathbf{g y} \mid \mathbf{x})=\alpha_{0} /\left(1-\alpha_{2}\right) \mathbf{1}+\alpha_{1} \mathbf{g x}+\left(\alpha_{1} \alpha_{2}+\alpha_{3}\right) \sum_{k=0}^{\infty}\left(\alpha_{2}\right)^{k} \mathbf{g}^{k+2} \mathbf{x}
$$

The remainder of the paper clarifies the conditions under which identification holds under network interaction.

\subsection{Results}

Our first result shows that the identification of social effects is related to a simple property of the matrix $\mathbf{g}$.

Proposition 1 Suppose that $\alpha_{1} \alpha_{2}+\alpha_{3} \neq 0$. If the matrices $\mathbf{i}, \mathbf{g}$, and $\mathbf{g}^{2}$ are linearly independent social effects are identified. If the matrices $\mathbf{i}, \mathbf{g}$, and $\mathbf{g}^{2}$ are linearly dependent and no individual is isolated, social effects are not identified.

It is worth noting that the first part of this result holds even if equation (2) is written with an arbitrary matrix $\mathbf{g}$, while the second part holds as soon as $\mathbf{g}$ is row-normalized. ${ }^{19}$ This includes situations where the network is weighted, or where the sum of outcomes and characteristics in the reference group matters, rather than the mean.

\footnotetext{
${ }^{18}$ Additional assumptions on the error terms, for example that they are i.i.d. (due to randomization of reference groups), could help identification (e.g., see Moffitt 2001).

${ }^{19}$ One easy way to check whether these three matrices are linearly independent is the following. First, one vectorizes each matrix, that is, one stacks its columns on top of each other. Second, one verifies whether the matrix formed by concatening these stacked vectors has rank three.
} 
The condition $\alpha_{1} \alpha_{2}+\alpha_{3} \neq 0$ is natural in this setting. As shown in (4), it means that others' characteristics have some (direct and/or indirect) effect on an individual's expected outcome. When it is violated, endogenous and exogenous effects are zero or exactly cancel out, and social effects are absent from the reduced form. The condition is satisfied as soon as $\alpha_{1}$ and $\alpha_{3}$ have the same sign, $\alpha_{2}>0$ and $\alpha_{1} \neq 0$. With several characteristics, it must be satisfied for at least one of them.

Proposition 1 can be given a natural interpretation in terms of instrumental variables. We show in Appendix 2 (Result 1) that when no individual is isolated, the matrices $\mathbf{i}, \mathbf{g}$, and $\mathbf{g}^{2}$ are linearly dependent if and only if $E(\mathbf{g y} \mid \mathbf{x})$ is perfectly collinear with $(\mathbf{1}, \mathbf{x}, \mathbf{g x}) .{ }^{20}$ This perfect collinearity means that we cannot find a valid (identifying) instrument for gy in the structural equation (2). In contrast, when $E(\mathbf{g y} \mid \mathbf{x})$ is not perfectly collinear with the regressors, the restrictions imposed by the network structure allow the model to be identified. From (5), it is clear that the variables $\left(\mathbf{1}, \mathbf{x}, \mathbf{g x}, \mathbf{g}^{2} \mathbf{x}, \mathbf{g}^{3} \mathbf{x}, \ldots\right)$ can be used as valid instruments and therefore can be used to consistently estimate the $\alpha$ 's. ${ }^{21}$

Here an important remark is in order. Up to now, we have assumed that we observe an i.i.d. sample of $\left(\mathbf{y}_{l}, \mathbf{x}_{l}\right)$ of size $L(l=1, \ldots, L)$ from a population of networks with a fixed and known structure (matrix $\mathbf{g}$ non-stochastic). Alternatively suppose that we observe an i.i.d. sample of $\left(\mathbf{y}_{l}, \mathbf{x}_{l}, \mathbf{g}_{l}\right)$ of size $L$, where the matrices $\mathbf{g}_{l}$ are now stochastic but strictly exogenous. Consider Proposition 1 in this case. As soon as one $\mathbf{g}$ in the support of the network's distribution is such that $\mathbf{i}, \mathbf{g}$, and $\mathbf{g}^{2}$ are linearly independent, then the model is identified. This is the case, since for identification purposes, the size of the sample can be as large as needed. If for every $\mathbf{g}$ in the support of the network's distribution, no individual is isolated, $\mathbf{i}, \mathbf{g}$, and $\mathbf{g}^{2}$ are linearly dependent, and they share a common relation of linear dependency, then the model is not identified. Propositions 4 and 6 below can be generalized in a similar way.

\footnotetext{
${ }^{20}$ This equivalence is subject to a minor technical condition.

${ }^{21}$ One can show that the potential number of instruments cannot exceed a critical level smaller or equal to the number of individuals in the network. Overidentification tests such as the one suggested by Lee (2003) for a spatial autoregressive model could be implemented.
} 


\subsubsection{Group Interactions}

In this section, we apply Proposition 1 to analyze identification when individuals interact in groups. We focus particularly on models developed by Manski (1993), Moffitt (2001) and Lee (2006).

Nonindentification in Manski's (1993) Model Let us first show how Proposition 1 covers Manski's first negative result discussed in the introduction. Suppose that individuals interact in groups, and also that the individual is included when computing the mean $\left(i \in N_{i}\right)$. That is, there is a partition of the population in subsets $G_{1}, . ., G_{k}$ such that for any $i \in G_{l}, N_{i}=G_{l}$. This means that individuals are affected by all others in their group and by none outside of it. The network of interaction is therefore the union of complete subnetworks. In this case, $\mathbf{g}^{2}=\mathbf{g}$, that is, $\mathbf{g}$ is idempotent. The second part of Proposition 1 applies. From (5), the expected mean outcome of the reference groups, $E(\mathbf{g y} \mid \mathbf{x})$, is given by $\alpha_{0} /\left(1-\alpha_{2}\right) \mathbf{1}+\left(\alpha_{1}+\alpha_{3}\right) /\left(1-\alpha_{2}\right) \mathbf{g x}$ and is therefore perfectly collinear with the mean characteristics of the group. Therefore, the list of valid instruments is $(\mathbf{1}, \mathbf{x}, \mathbf{g x})$. In this model, no matter the group sizes, social effects are not identified.

Nonindentification in Moffitt's (2001) Model Alternatively, as in Moffitt (2001), suppose that individuals interact in a unique group, and that the individual is excluded when computing the mean $\left(i \notin N_{i}\right)$. Denote by $\boldsymbol{\omega}_{n}$ the corresponding interaction matrix where $\omega_{i j}=1 /(n-1)$ if $i \neq j$ and 0 otherwise. It is easy to see that $\boldsymbol{\omega}_{n}^{2}=\frac{1}{n-1} \mathbf{i}+\frac{n-2}{n-1} \boldsymbol{\omega}_{n}$ if $n \geq 2$, and the second part of Proposition 1 again applies. Social effects are not identified.

Identification in Lee's (2006) Model Suppose now that individuals interact in two groups of sizes $n_{1}$ and $n_{2}$ with $n_{1}, n_{2} \geq 2$. The interaction matrix $\mathbf{g}$ can be written as follows

$$
\mathbf{g}=\left(\begin{array}{cc}
\boldsymbol{\omega}_{n_{1}} & 0 \\
0 & \boldsymbol{\omega}_{n_{2}}
\end{array}\right)
$$


Suppose that $\mathbf{g}^{2}=\lambda_{0} \mathbf{i}+\lambda_{1} \mathbf{g} .{ }^{22}$ The diagonal elements give $\lambda_{0}=1 /\left(n_{1}-1\right)=1 /\left(n_{2}-1\right)$, hence $n_{1}=n_{2}$. Therefore, if $n_{1} \neq n_{2}$, the matrices $\mathbf{i}, \mathbf{g}$, and $\mathbf{g}^{2}$ are linearly independent, the first part of Proposition 1 applies. Moreover, using eq. (5), one can easily show that $E(\mathbf{g y} \mid \mathbf{x})=$ $\alpha_{0} /\left(1-\alpha_{2}\right) \mathbf{1}+\beta_{0} \mathbf{x}+\beta_{1} \mathbf{g x}+\beta_{2} \mathbf{g}^{2} \mathbf{x}$, with $\beta_{2} \neq 0$ when $\alpha_{2} \neq 0$ and $\alpha_{1} \alpha_{2}+\alpha_{3} \neq 0 .{ }^{23}$ Therefore, the variables $\left(\mathbf{1}, \mathbf{x}, \mathbf{g x}, \mathbf{g}^{2} \mathbf{x}\right)$ can be used as valid instruments for $\mathbf{g y}$. In this model, social effects are identified. This result is related to Lee (2006)'s model in the absence of group fixed effects.

Proposition 2 Suppose that individuals interact in groups. If all groups have the same size, social effects are not identified. If (at least) two groups have different sizes, and if $\alpha_{1} \alpha_{2}+\alpha_{3} \neq 0$, social effects are identified.

Identification arises here thanks to the effects of the group size on reduced form coefficients within each group. After some manipulations, eq. (3) can be rewritten as follows:

$$
y_{i}=\frac{\alpha_{0}}{1-\alpha_{2}}+\left[\alpha_{1}+\frac{\alpha_{2}\left(\alpha_{1} \alpha_{2}+\alpha_{3}\right)}{\left(1-\alpha_{2}\right)\left(n_{g}-1+\alpha_{2}\right)}\right] x_{i}+\frac{\alpha_{1} \alpha_{2}+\alpha_{3}}{\left(1-\alpha_{2}\right)\left(1+\frac{\alpha_{2}}{n_{g}-1}\right)} \bar{x}_{i}+\nu_{i},
$$

where $n_{g}$ is the size of $i$ 's group, and $\bar{x}_{i}$ is the mean over all other individuals in the group and $\nu_{i}$ is the error term. Variation of reduced form coefficients across groups of different size allows to identify the structural model. The impact of $n_{g}$ on these coefficients has an intuitive interpretation. Consider first the reduced form coefficient on $x_{i}$ in (6). It is the sum of a direct and an indirect effect. The direct effect is simply equal to $\alpha_{1}$, and captures the effect of $i$ 's characteristic on $i$ 's outcome already present in the structural model. The indirect effect arises through endogenous effects: $x_{i}$ affects $y_{j}$, which in turn, affects $y_{i}{ }^{24}$ The indirect effects decrease with $n_{g}$, and become negligible as $n_{g}$ tends to infinity. This reflects the diminishing role that $i$ plays, by himself, in determining others' outcomes when the size of the group grows. For a similar reason, the reduced form coefficient on $\bar{x}_{i}$ is increasing in $n_{g}$. As the role played by one individual decreases, the mean characteristics of all the others become more important.

\footnotetext{
${ }^{22}$ Observe that, since at least one individual is not isolated, the matrices $\mathbf{i}$ and $\mathbf{g}$ are linearly independent.

${ }^{23}$ After few manipulations, one obtains: $\beta_{2}=\left[\left(\alpha_{1} \alpha_{2}+\alpha_{3}\right) \alpha_{2}\right] /\left(1-\lambda_{2} \alpha_{2}-\lambda_{1} \alpha_{2}^{2}-\lambda_{0} \alpha_{2}^{3}\right)$, where $\lambda_{0}=$ $\frac{1}{\left(n_{1}-1\right)\left(n_{2}-1\right)}, \lambda_{1}=\frac{n_{1}+n_{2}-3}{\left(n_{1}-1\right)\left(n_{2}-1\right)}$, and $\lambda_{2}=\frac{n_{1} n_{2-2}\left(n_{1}+n_{2}\right)+3}{\left(n_{1}-1\right)\left(n_{2}-1\right)}$.

${ }^{24}$ This indirect effect itself has different channels: $x_{i}$ affects $y_{j}$ both directly through exogenous effects $\left(\alpha_{3}\right)$, and indirectly through endogenous effects $\left(\alpha_{2}\right)$ via its effects on $y_{i}\left(\alpha_{1}\right)$ and $y_{k}\left(\alpha_{3}\right)$.
} 
Thus, variations in group sizes create exogenous variations in the reduced form coefficients across groups that lead to identification. Interestingly, Davezies et al. (2006) have shown that Lee's model is generically identified, even when all members in the group are not observed. Observe finally that, in this model, social effects may be identified when the individual is excluded in the computation of the group mean, but not when he is included.

\subsubsection{Network Interactions}

Suppose now that individuals interact through a network. In addition, suppose that we can find an intransitive triad in the network. This is a set of three agents $i, j, k$ such that $i$ is affected by $j$ and $j$ is affected by $k$, but $i$ is not affected by $k$. In this case, $g_{i k}=0$ while $g_{i k}^{2} \geq g_{i j} g_{j k}>0$. In contrast, $\mathbf{g}^{2}=\lambda_{0} \mathbf{i}+\lambda_{1} \mathbf{g}$ implies that $g_{i k}^{2}=0$. Therefore, the presence of an intransitive triad guarantees that $\mathbf{i}, \mathbf{g}$, and $\mathbf{g}^{2}$ are linearly independent. This means that $\mathbf{g}^{2} \mathbf{x}$ is a valid instrument for gy, since $x_{k}$ affects $y_{i}$ but only indirectly, through its effect on $y_{j}$ (that is, through a link of distance 2).

Most networks have intransitive triads. ${ }^{25}$ Some networks do not, however. They are called transitive, and are characterized by specific properties, e.g., see Bang-Jensen and Cutin (2000). We analyze the case of transitive networks in Appendix 1. We show that for most of them, the first part of Proposition 1 applies. More precisely, we show that $\mathbf{i}, \mathbf{g}$, and $\mathbf{g}^{2}$ are linearly independent if and only if $\mathbf{g}^{2} \neq 0$. In this case, the variables $\left(\mathbf{1}, \mathbf{x}, \mathbf{g x}, \mathbf{g}^{2} \mathbf{x}\right)$ can be used as valid instruments for $\mathbf{g y}$. When $\mathbf{g}^{2}=0$, the first part of Proposition 1 obviously does not apply. ${ }^{26}$ However, the presence of isolated individuals still yields identification. Indeed, $\alpha_{0}$ and $\alpha_{1}$ can be identified from the reduced form parameters of isolated individuals. Also, $\alpha_{2}$ can be identified from the constant of the reduced form of non-isolated individuals (i.e., $\left.\frac{\alpha_{0}}{1-\alpha_{2}}\right)$ as long as $\alpha_{0} \neq 0$. Finally, $\alpha_{3}$ is identified from the coefficient associated with $\mathbf{x}$ in (3). In the end, we obtain the following result.

Proposition 3 Suppose that individuals do not interact in groups. Suppose that $\alpha_{1} \alpha_{2}+\alpha_{3} \neq 0$. If $\mathbf{g}^{2} \neq 0$, social effects are identified. If $\mathbf{g}^{2}=0$, social effects are identified when $\alpha_{0} \neq 0$, but not

\footnotetext{
${ }^{25}$ Especially, if individuals do not interact in groups, any symmetric network has an intransitive triad. Symmetric networks are such that $j \in N_{i} \Rightarrow i \in N_{j}$. They arise naturally in certain contexts, like co-authorship.

${ }^{26}$ Networks such that $\mathbf{g}^{2}=0$ do not have any triad. Any individual either affect others, or is affected by others. These structures correspond to bipartite unidirectional networks.
} 
when $\alpha_{0}=0$.

Overall, the results presented in this section show that endogenous and exogenous effects can usually be identified as soon as there is some variation in the reference groups. The results are clear-cut, reflecting the theoretical nature of identification conditions. In practice though, we expect identification to be weak if the network is close to being complete, or if individuals interact in groups and group sizes are large. We explore this issue in Section 4.

\section{Correlated Effects}

In this section, we partially address the problem of correlated effects. We introduce unobserved variables common to individuals who belong to the same component of the network. These variables may be correlated with individual observable characteristics, which introduces an additional identification problem. As in panel data models, we solve this problem by taking appropriate differences between outcomes to take out the unobserved variables. We then ask whether endogenous and exogenous social effects can be disentangled. We characterize the necessary and sufficient conditions for identification. Not surprisingly, these conditions are more demanding than in the absence of correlated effects. Identification still holds in most networks, but it fails for some specific ones. We also find that the way common unobservables are eliminated matters. We provide the best possible condition for identification in this setting.

\subsection{The Model}

We introduce component-level unobservables in the previous model. The components of a network are defined as follows (see Wasserman and Faust 1994). ${ }^{27}$ Two individuals $i$ and $j$ are related if $j \in N_{i}$ or $i \in N_{j}$. They are indirectly related if they are related, or if there is a chain of individuals $i_{1}, \ldots, i_{l}$ such that the pairs $i$ and $i_{1}, i_{1}$ and $i_{2}, \ldots, i_{l}$ and $j$ are related. A component is a maximal set of indirectly related individuals. Components provide a natural partition of the population. Denote by $C$ the set of components and by $|C|$ its cardinality (i.e., their number).

\footnotetext{
${ }^{27}$ Two types of components can be defined on directed graphs. They are called weak and strong components in the literature on social networks. We consider here weak components. See the proof of Proposition 3 for a discussion of strong components. Weak and strong components coincide when relations are undirected.
} 
We observe that when individuals interact in groups within the network, components are simply equal to the groups. We consider the following structural model. For any component $c$ and for any individual $i$ belonging to $c$,

$$
y_{i}=\mu_{c}+\alpha_{1} x_{i}+\alpha_{2} \frac{\sum_{j \in N_{i}} y_{j}}{n_{i}}+\alpha_{3} \frac{\sum_{j \in N_{i}} x_{j}}{n_{i}}+\epsilon_{i}
$$

The component fixed effect $\mu_{c}$ captures unobserved (by the modeler) variables that have common effects on the outcome of all agents within the component. Importantly, $E\left(\mu_{c} \mid \mathbf{x}\right)$ may be different from zero for all $i \in c$ but we assume that $E\left(\epsilon_{i} \mid \boldsymbol{\mu}_{\mathbf{c}}, \mathbf{x}\right)=0$. Thus, correlated unobservables may be present but we maintain the strict exogeneity of $\mathbf{x}$, given $\boldsymbol{\mu}_{\mathbf{c}}$. This is a natural generalization of the model of Lee (2006) to a network setting. A similar model has been estimated by Lin (2005).

The structural model (7) captures different types of correlated effects. Individuals in the same component can face a common environment. The model is also consistent with two-step processes of link formation. For instance, suppose that individuals join clubs first, and then forms links with others in their club. Individuals may have different types, capturing preferences over social relations. If individuals self-select into clubs based on their types, then conditional on belonging to a club, link formation may be uncorrelated with individual characteristics.

Before studying how the reflection problem can be solved in this context, the standard approach is first to eliminate the component-level unobservables. In analogy with the within transformation in panel data models, this can be done by taking appropriate differences between structural equations. However there are many transformations that can eliminate the unobservables. We next study two natural ways to do that. Throughout this section, we assume that no individual is isolated. More generally, our results are valid for any row-normalized matrix $\mathbf{g}$.

\subsection{Local Differences}

We first take local differences. We average equation (7) over all the neighbors of $i$ (that is, all individuals $j$ such that $j \in N_{i}$ ), and subtract from $i$ 's equation. This approach is local since it does not fully exploit the fact that the fixed effect is not only the same for all neighbors of $i$ but also for all individuals of his component. Written in matrix notations, the structural model, on 
which a within local transformation is applied, becomes:

$$
(\mathbf{i}-\mathbf{g}) \mathbf{y}=\alpha_{1}(\mathbf{i}-\mathbf{g}) \mathbf{x}+\alpha_{3}(\mathbf{i}-\mathbf{g}) \mathbf{g x}+\alpha_{2}(\mathbf{i}-\mathbf{g}) \mathbf{g y}+(\mathbf{i}-\mathbf{g}) \boldsymbol{\epsilon}
$$

The corresponding reduced form is obtained as in Section 2 (see eq. (3)).

$$
(\mathbf{i}-\mathbf{g}) \mathbf{y}=\left(\mathbf{i}-\alpha_{2} \mathbf{g}\right)^{-1}\left(\alpha_{1} \mathbf{i}+\alpha_{3} \mathbf{g}\right)(\mathbf{i}-\mathbf{g}) \mathbf{x}+\left(\mathbf{i}-\alpha_{2} \mathbf{g}\right)^{-1}(\mathbf{i}-\mathbf{g}) \boldsymbol{\epsilon} .
$$

Our next result characterizes identification in this setting.

Proposition 4 Consider model (8). Suppose that $\alpha_{1} \alpha_{2}+\alpha_{3} \neq 0$. Social effects are identified if and only if the matrices $\mathbf{i}, \mathbf{g}, \mathbf{g}^{2}$, and $\mathbf{g}^{3}$ are linearly independent.

This condition is more demanding than the condition of Proposition 1. Some information has been lost to take into account the presence of correlated effects. This loss makes identification more difficult. The following property may be useful in applications (e.g., see Horn and Johnson 1985). If the matrix $\mathbf{g}$ has (at least) four different eigenvalues, then $\mathbf{i}, \mathbf{g}, \mathbf{g}^{2}$, and $\mathbf{g}^{3}$ are linearly independent. If $\mathbf{g}$ has three different eigenvalues (or less) and $\mathbf{g}$ is diagonalizable, then $\mathbf{i}, \mathbf{g}, \mathbf{g}^{2}$, and $\mathbf{g}^{3}$ are linearly dependent.

As in the previous section, Proposition 4 has a natural interpretation in terms of instrumental variables. We show in Appendix 2 (Result 2) that the matrices $\mathbf{i}, \mathbf{g}, \mathbf{g}^{2}$, and $\mathbf{g}^{3}$ are linearly dependent if and only if the expected value of the endogenous variable on the right-hand side of equation (8), $E[(\mathbf{i}-\mathbf{g}) \mathbf{g y} \mid \mathbf{x}]$, is perfectly collinear with the regressors $((\mathbf{i}-\mathbf{g}) \mathbf{x},(\mathbf{i}-\mathbf{g}) \mathbf{g x})$. When this perfect collinearity holds, the structural model is clearly not identified. Again, from a series expansion of $E[(\mathbf{i}-\mathbf{g}) \mathbf{g y} \mid \mathbf{x}]$ similar to the one in eq. (5), it is clear that when $E[(\mathbf{i}-\mathbf{g}) \mathbf{g y} \mid \mathbf{x}]$ is not perfectly collinear with the regressors, the variables $\left.((\mathbf{i}-\mathbf{g}) \mathbf{x},(\mathbf{i}-\mathbf{g}) \mathbf{g x}),(\mathbf{i}-\mathbf{g}) \mathbf{g}^{2} \mathbf{x},(\mathbf{i}-\mathbf{g}) \mathbf{g}^{3} \mathbf{x}, \ldots\right)$ can be used as valid instruments for $(\mathbf{i}-\mathbf{g}) \mathbf{g y}$.

We study the implications of Proposition 4 on the pattern of interactions among individuals. Consider group interactions. Three different sizes are now necessary to obtain identification. With two groups of sizes $n_{1}$ and $n_{2}$, we can see that $\mathbf{i}, \mathbf{g}, \mathbf{g}^{2}$, and $\mathbf{g}^{3}$ are linearly dependent. More precisely,

$$
\mathbf{g}^{3}=\frac{1}{\left(n_{1}-1\right)\left(n_{2}-1\right)} \mathbf{i}+\frac{n_{1}+n_{2}-3}{\left(n_{1}-1\right)\left(n_{2}-1\right)} \mathbf{g}+\frac{n_{1} n_{2}-2\left(n_{1}+n_{2}\right)+3}{\left(n_{1}-1\right)\left(n_{2}-1\right)} \mathbf{g}^{2} .
$$


In contrast, with three sizes (or more), $\mathbf{i}, \mathbf{g}, \mathbf{g}^{2}$, and $\mathbf{g}^{3}$ are linearly independent, and social effects are identified (see Davezies et al. 2006). ${ }^{28}$ This is, of course, confirmed by looking directly at the reduced form. Let $n_{g}$ be the size of $i$ 's group. Equation (9) becomes

$$
y_{i}-\bar{y}=\frac{\left(n_{g}-1\right) \alpha_{1}-\alpha_{3}}{\left(n_{g}-1\right)+\alpha_{2}}\left(x_{i}-\bar{x}\right)+\frac{n_{g}-1}{n_{g}-1+\alpha_{2}}\left(\epsilon_{i}-\bar{\epsilon}\right)
$$

where means are computed over all individuals in $i$ 's group. (See eq. 2.5 in Lee 2006). Only one composite parameter can now be recovered from the reduced form for each group size. Three sizes are thus needed to identify the three structural parameters.

Next, consider network interaction. Intransitive triads have a natural counterpart. Define the distance between two individuals $i$ and $j$ in the network as the number of links connecting $i$ and $j$ in the shortest chain of individuals $i_{1}, \ldots, i_{l}$ such that $i_{1} \in N_{i}, i_{2} \in N_{i_{1}}, \ldots, j \in N_{i_{l}}{ }^{29}$ For instance, this distance is 1 between two individuals directly connected and 2 in an intransitive triad. Define the diameter of the network as the maximal distance between any two individuals in the network. Suppose that we can find two individuals $i$ and $j$ separated by a distance 3 in the network. In this case, $g_{i j}^{3}>0$ while $g_{i j}^{2}=g_{i j}=0$. Hence, no linear relation of the form $\mathbf{g}^{3}=\lambda_{0} \mathbf{i}+\lambda_{1} \mathbf{g}+\lambda_{2} \mathbf{g}^{2}$ can exist. Therefore, one has:

Corollary 5 Consider model (8) and suppose that $\alpha_{1} \alpha_{2}+\alpha_{3} \neq 0$. If the diameter of the network is greater than or equal to 3 , social effects are identified.

This condition is satisfied in most networks. As in Section 2, it can be understood in terms of instrumental variables. Let $i, i_{1}, i_{2}, j$ be a path of minimal length connecting $i$ to $j$. Observe that now $y_{i}-\frac{1}{n_{i}} \sum_{k \in N_{i}} y_{k}$ has to be explained as a function of exogenous variables and of $\frac{1}{n_{i}} \sum_{k \in N_{i}}\left(y_{k}-\right.$ $\left.\frac{1}{n_{k}} \sum_{l \in N_{k}} y_{l}\right)$. Also, $i_{1} \in N_{i}$ and $i_{2} \in N_{i_{1}}$. The exogenous characteristic $x_{i_{2}}$ is not a valid instrument to estimate the endogenous social effect, since $y_{i_{2}}$ directly appears on the right-hand side. In contrast, $y_{j}$ does not appear on the right-hand side, hence $x_{j}$ affects $y_{i}$ only indirectly through its effect on $y_{i_{2}}$. Therefore, $x_{j}$ is a valid instrument to estimate the endogenous social effect, and the model is identified. From the series expansion of the model, this means that the

\footnotetext{
${ }^{28}$ With three groups of sizes $n_{1}, n_{2}$ and $n_{3}$, the matrix $\mathbf{g}$ is diagonalizable and has four distinct eigenvalues: $1,-1 /\left(n_{1}-1\right),-1 /\left(n_{2}-1\right)$, and $-1 /\left(n_{3}-1\right)$.

${ }^{29}$ If there is no chain of individuals connecting $i$ and $j$, by convention the distance between them is equal to 0 .
} 
variables $\left.((\mathbf{i}-\mathbf{g}) \mathbf{x},(\mathbf{i}-\mathbf{g}) \mathbf{g x}),(\mathbf{i}-\mathbf{g}) \mathbf{g}^{2} \mathbf{x}\right)$ are valid instruments for the right-hand side endogenous vector $(\mathbf{i}-\mathbf{g})$ gy.

Identification fails, however, for a number of non trivial networks of diameter lower than or equal to 2 . This is notably the case for complete bipartite networks. In these graphs, population is divided in two subgraphs such that all individuals in one subgraph are connected to all individuals in the other subgraph, and there is no connection within subgraphs. These include star networks, where one agent, at the center, is connected to all the other agents, who are all only connected to him. It is easy to check that $\mathbf{g}^{3}=\mathbf{g}$ for complete bipartite networks. By Proposition 4 , social effects are not identified for these networks. To illustrate, consider star networks. Let $i=1$ denote the center. Reduced form equation (9) for star networks can be expressed as follows:

$$
\begin{aligned}
y_{1}-\frac{1}{n-1} \sum_{j=2}^{n} y_{j} & =\frac{\alpha_{1}-\alpha_{3}}{1+\alpha_{2}}\left(x_{1}-\frac{1}{n-1} \sum_{j=2}^{n} x_{j}\right)+\nu_{1}, \text { or } \\
y_{i}-y_{1} & =\alpha_{1}\left(x_{i}-x_{1}\right)+\left(\alpha_{1}-\frac{\alpha_{1}-\alpha_{3}}{1+\alpha_{2}}\right)\left(x_{1}-\frac{1}{n-1} \sum_{j=2}^{n} x_{j}\right)+\nu_{2}, \forall i \geq 2 .
\end{aligned}
$$

We can only recover the two composite parameters $\alpha_{1}$ and $\frac{\alpha_{1}-\alpha_{3}}{1+\alpha_{2}}$ from the estimation of the reduced form. This makes the identification of the three structural parameters impossible.

We could not fully characterize the condition of Proposition 4 in terms of the geometry of the network. To gain some insight on this issue, we determined all the connected non directed networks for which identification fails when $n=4,5$, and 6 . They are depicted in Figure 1 . We observe two features. First, the number of networks for which identification fails is relatively low, even within the set of networks with diameter lower than or equal to 2. Second, all these networks exhibit a high degree of symmetry. We suspect that both features hold more generally. Linear dependence between $\mathbf{i}, \mathbf{g}, \mathbf{g}^{2}$, and $\mathbf{g}^{3}$ likely imposes strong restrictions on the network's geometry.

\subsection{Global Differences}

We next take global differences. We average equation (7) over all individuals in $i$ 's component, and subtract from $i$ 's equation. In contrast with the previous section, the equation being subtracted is now identical for all individuals in the same component. Introduce the matrix $\mathbf{h}$ as follows: $h_{i j}=\frac{1}{|c|}$ if $i$ and $j$ belong to $c$, and $h_{i j}=0$ otherwise. The $i$ th element of $\mathbf{h x}$ equals the average of $\mathbf{x}$ over $i$ 's component. Also, for any component $c$, let $\mathbf{1}_{c}$ denote the vector whose $i$ th element is 1 if 
$i \in c$ and 0 otherwise. We can write the structural model on which a global within transformation is applied as follows:

$$
(\mathbf{i}-\mathbf{h}) \mathbf{y}=\alpha_{1}(\mathbf{i}-\mathbf{h}) \mathbf{x}+\alpha_{3}(\mathbf{i}-\mathbf{h}) \mathbf{g x}+\alpha_{2}(\mathbf{i}-\mathbf{h}) \mathbf{g y}+(\mathbf{i}-\mathbf{h}) \boldsymbol{\epsilon}
$$

In this context, the restricted reduced form becomes: ${ }^{30}$

$$
(\mathbf{i}-\mathbf{h}) \mathbf{y}=(\mathbf{i}-\mathbf{h})\left(\mathbf{i}-\alpha_{2} \mathbf{g}\right)^{-1}\left(\alpha_{1} \mathbf{i}+\alpha_{3} \mathbf{g}\right) \mathbf{x}+(\mathbf{i}-\mathbf{h})\left(\mathbf{i}-\alpha_{2} \mathbf{g}\right)^{-1} \boldsymbol{\epsilon}
$$

We characterize the condition under which this model is identified. Our result involves the rank of the matrix $\mathbf{i}-\mathbf{g}$. Since $\forall c \in C,(\mathbf{i}-\mathbf{g}) \mathbf{1}_{c}=\mathbf{0}$, this rank is always lower than or equal to $n-|C| \cdot{ }^{31}$

Proposition 6 Consider model (11). Suppose that $\alpha_{1} \alpha_{2}+\alpha_{3} \neq 0$. If the matrices $\mathbf{i}, \mathbf{g}, \mathbf{g}^{2}$, and $\mathbf{g}^{3}$ are linearly independent, social effects are identified. Next, suppose that $\mathbf{g}^{3}=\lambda_{0} \mathbf{i}+\lambda_{1} \mathbf{g}+\lambda_{2} \mathbf{g}^{2}$. If $\operatorname{rank}(\mathbf{i}-\mathbf{g})<n-|C|$ and $2 \lambda_{0}+\lambda_{1}+1 \neq 0$, social effects are identified. In contrast, if $\operatorname{rank}(\mathbf{i}-\mathbf{g})=n-|C|$, social effects are not identified. ${ }^{32}$

From a demonstration similar to the one used in in Result 2 of Appendix 2, one shows that the model is not identified if and only if $E[(\mathbf{i}-\mathbf{h})) \mathbf{g y} \mid \mathbf{x}]$ is perfectly collinear with the regressors $((\mathbf{i}-\mathbf{h}) \mathbf{x},(\mathbf{i}-\mathbf{h}) \mathbf{g x})$. Moreover, the variables $\left((\mathbf{i}-\mathbf{h}) \mathbf{x},(\mathbf{i}-\mathbf{h}) \mathbf{g x},(\mathbf{i}-\mathbf{h}) \mathbf{g}^{2} \mathbf{x}, \ldots\right)$ can be used as valid instruments to estimate the model consistently, when the model is identified.

The result shown in Proposition 6 implies that if social effects are identified when taking local differences, they are also identified when taking global differences. The reverse need not be true, however, as the example below demonstrates. The condition $\operatorname{rank}(\mathbf{i}-\mathbf{g})<n-|C|$ means that

\footnotetext{
${ }^{30}$ Since $\mathbf{i}-\mathbf{h}$ and $\left(\mathbf{i}-\alpha_{2} \mathbf{g}\right)^{-1}$ do not generally commute, the reduced-form cannot be obtained directly from equation (11). Rather, rewrite equation (7) as follows:

$$
\mathbf{y}=\sum_{c} \mu_{c} \mathbf{1}_{c}+\alpha_{1} \mathbf{x}+\alpha_{2} \mathbf{g y}+\alpha_{3} \mathbf{g x}+\boldsymbol{\epsilon}
$$

Isolate $\mathbf{y}$ :

$$
\mathbf{y}=\sum_{c} \frac{\mu_{c}}{1-\alpha_{2}} \mathbf{1}_{c}+\left(\mathbf{i}-\alpha_{2} \mathbf{g}\right)^{-1}\left(\alpha_{1} \mathbf{i}+\alpha_{3} \mathbf{g}\right) \mathbf{x}+\left(\mathbf{i}-\alpha_{2} \mathbf{g}\right)^{-1} \boldsymbol{\epsilon}
$$

and multiply by $\mathbf{i}-\mathbf{h}$.

${ }^{31}$ The vectors $\mathbf{1}_{c}$ are linearly independent, hence $\operatorname{dim} \operatorname{Ker}(\mathbf{i}-\mathbf{g}) \geq|C|$. Since $\operatorname{dim} \operatorname{Ker}(\mathbf{i}-\mathbf{g})+\operatorname{rank}(\mathbf{i}-\mathbf{g})=n$, $\operatorname{rank}(\mathbf{i}-\mathbf{g}) \leq n-|C|$.

${ }^{32}$ The case where $\operatorname{rank}(\mathbf{i}-\mathbf{g})<n-|C|$ and $2 \lambda_{0}+\lambda_{1}+1=0$ is covered in the Appendix. It involves a more elaborate condition.
} 
we can find a vector $\mathbf{x}$ such that $\mathbf{g x}=\mathbf{x}$ and for some $i, j$ belonging to the same component, $x_{i} \neq x_{j}$. For many networks, the conditions in Propositions 4 and 6 are identical. Under group interactions, both ways of removing the common group unobservables are equivalent. This can be seen directly on the reduced form. Equation (12) is equivalent to equation (9). Alternatively, we can apply Proposition 6 . With two groups of sizes $n_{1} \neq n_{2},|C|=2$, and $\operatorname{rank}(\mathbf{i}-\mathbf{g})=n-2$. Social effects are not identified under either way of eliminating the unobservables. Similarly, we can check that $\operatorname{rank}(\mathbf{i}-\mathbf{g})=n-|C|$, hence that identification fails, for the networks depicted in Figure 1 and for complete bipartite networks.

The two conditions are not equivalent, however. There are networks for which social effects are identified when taking global differences, but not when taking local differences. We give an example in Figure 2 with $n=5$. This network has a unique component. The matrix $\mathbf{g}$ satisfies $\mathbf{g}^{3}=\mathbf{g}$, hence identification fails when taking local differences. However, $\operatorname{rank}(\mathbf{i}-\mathbf{g})=3<$ $n-|C|=4$ and $2 \lambda_{0}+\lambda_{1}+1=2 \neq 0$. Thus, identification holds when taking global differences. The way correlated effects are addressed affects the way endogenous and exogenous social effects can be identified.

We next show that Proposition 6 gives the best possible condition for identification. If social effects are not identified when subtracting the component's average, they are never identified. We consider some arbitrary linear combinations of the structural equations designed to remove the $\mu_{c}$ 's. Let $\mathbf{d}$ be the corresponding $n \times n$ differentiation matrix. For instance, $\mathbf{d}=\mathbf{i}-\mathbf{g}$ when subtracting the average over individuals' neighbors, and $\mathbf{d}=\mathbf{i}-\mathbf{h}$ when subtracting the component's average. To eliminate the component-level unobservables, $\mathbf{d}$ must satisfy $\forall c \in C$, $\mathbf{d} \mathbf{1}_{c}=\mathbf{0}$. Hence, $\operatorname{rank}(\mathbf{d}) \leq n-|C|$. Denote by $\operatorname{ker} \mathbf{d}=\{\mathbf{x}: \mathbf{d x}=\mathbf{0}\}$ the kernel of $\mathbf{d}$. Applying $\mathbf{d}$, the structural model becomes $\mathbf{d} \mathbf{y}=\alpha_{1} \mathbf{d x}+\alpha_{3} \mathbf{d g x}+\alpha_{2} \mathbf{d g} \mathbf{y}+\mathbf{d} \boldsymbol{\epsilon}$ with associated reduced form $\mathbf{d y}=\mathbf{d}\left(\mathbf{i}-\alpha_{2} \mathbf{g}\right)^{-1}\left(\alpha_{1} \mathbf{i}+\alpha_{3} \mathbf{g}\right) \mathbf{x}+\mathbf{d}\left(\mathbf{i}-\alpha_{2} \mathbf{g}\right)^{-1} \boldsymbol{\epsilon}$.

Proposition $\mathbf{7}$ Let $\mathbf{d}$ and $\mathbf{d}^{\prime}$ be two differentiation matrices such that $\operatorname{ker} \mathbf{d} \subset \operatorname{ker} \mathbf{d}^{\prime}$. If social effects are identified for the network $\mathbf{g}$ and the matrix $\mathbf{d}^{\prime}$, then they are identified for the same network and the matrix $\mathbf{d}$.

This result says that prospects for identification improve when the differentiation matrix has a smaller kernel. Observing that $\mathbf{i}-\mathbf{h}$ has maximal rank, we conclude that the condition described in Proposition 6 is the best possible condition for identification. 
Corollary 8 If social effects are identified for the network $\mathbf{g}$ and any differentiation matrix $\mathbf{d}$, then they are identified for the same network when subtracting the component's average.

\section{Monte Carlo Simulations}

In this section, we report results from Monte Carlo simulations. We focus on the baseline model (1). Proposition 3 shows that social effects are identified if individuals do not interact in groups. In practice, however, we expect identification to be weak if the graph is close to be complete (i.e., when its density is close to one). We study here how the strength of the identification is affected by the density of the graph and its degree of intransitivity, for various types of graphs. We find that structural parameters are better estimated when the density of the graph is small. The impact of intransitivity on the precision of estimators is however more complex and can be U-shaped for graphs with intermediate to high density.

\section{$4.1 \quad$ Networks}

We define the density and the level of intransitivity of a network (see Wasserman and Faust 1994). Density is equal to the ratio of the number of links over the total number of possible links. It describes the average probability that any two individuals are connected. The level of intransitivity is the ratio of the number of intransitive triads, where $i$ is connected to $j$ and $j$ to $k$ but $i$ is not connected to $k$, over the number of triads, where $i$ is connected to $j$ and $j$ to $k$ (and $k \neq i$ ). The intransitivity level lies between 0 and 1 ; it equals 0 only when the network is transitive.

We consider two types of networks. We first look at the standard Erdös-Rényi (1959) model of random graphs. Link are i.i.d. and each pair of individuals is connected with the same probability $d$. In this case, the expected density is equal to $d$ while the expected level of intransitivity is $1-d$. When $d=1$, the network is complete and social effects are not identified. We examine how the strength of identification changes when $d$ varies from 1 to 0.05 by increments of -0.05 .

Erdos-Rényi random graphs provide a natural starting point, but their structure is very specific. Especially, a lower $d$ corresponds to a lower density and a higher intransitivity. In order to disentangle both effects, we introduce a second type of graphs. We adapt the small-world procedure of Watts and Strogatz (1998) to our context. We start from disjoint complete sub- 
graphs of size $k$. (Hence $k$ divides the population size $n$ ). Then, with probability $p$ each link is rewired at random. Since the total number of links is constant, density is fixed and equal to $\frac{k-1}{n-1}$. We let the probability $p$ vary. When $p$ equals 0 , the level of intransitivity is 0 . When $p$ equals 1, we obtain an Erdös-Rényi graph. As $p$ increases, the expected level of intransitivity increases. We set $n=100$ and we let $k$ and $p$ takes the following values: $k \in\{4,5,10,20,25,50\}$ and $p \in\{0.01,0.05,0.1,0.2,0.4,0.6,0.8,1\} .{ }^{33}$ In summary, the second type of graphs allows us to look at how intransitivity affects the strength of identification, holding density constant. Also, they can be used to analyse the impact of density, holding intransitivity constant.

\subsection{Estimation}

We implement our baseline model, i.e.,

$$
\mathbf{y}=\alpha_{0}+\alpha_{1} \mathbf{x}+\alpha_{2} \mathbf{g y}+\alpha_{3} \mathbf{g x}+\boldsymbol{\epsilon} .
$$

Structural parameters are chosen as follows

$$
\alpha_{0}=3, \alpha_{1}=0.75, \alpha_{2}=0.5, \alpha_{3}=0.7 \text {. }
$$

In this model, $\boldsymbol{\epsilon}$ is a $n \times 1$ vector of disturbances which is $N(\mathbf{0}, \boldsymbol{\Sigma})$. We set $\boldsymbol{\Sigma}=\sigma^{2} \mathbf{i}$ and $\sigma^{2}=1 .^{34}$ $\mathbf{x}$ is a $n \times 1$ vector of observations on the exogenous variables. We draw one observation from the network. Regressors $x_{i}$ are i.i.d., picked from a uniform distribution on [0,50]. Finally, we generate the $n \times 1$ vector of endogenous variables $\mathbf{y}$ thanks to the reduced-form equation (3): $\mathbf{y}=\alpha_{0} /\left(1-\alpha_{2}\right) \mathbf{1}+\left(\mathbf{i}-\alpha_{2} \mathbf{g}\right)^{-1}\left(\alpha_{1} \mathbf{i}+\alpha_{3} \mathbf{g}\right) \mathbf{x}+\left(\mathbf{i}-\alpha_{2} \mathbf{g}\right)^{-1} \boldsymbol{\epsilon}$.

Social effects are estimated following a Generalized 2SLS strategy proposed in Kelejian and Prucha (1998) and refined in Lee (2003). This procedure yields an asymptotically optimal IV estimator and reduces to a two-step estimation method in our case. The first step consists in estimating a 2SLS using as instruments $\mathbf{S}=\left[\begin{array}{llll}\mathbf{1} & \mathbf{x} & \mathbf{g x} & \mathbf{g}^{2} \mathbf{x}\end{array}\right]$. In our case, the model is just identified, and we obtain $\widehat{\boldsymbol{\alpha}}^{2 S L S}=\left(\mathbf{S}^{\prime} \mathbf{X}\right)^{-1} \mathbf{S}^{\prime} \mathbf{y}$ where $\mathbf{X}=\left[\begin{array}{llll}\mathbf{1} & \mathbf{x} & \mathbf{g y} & \mathbf{g x}\end{array}\right]$ is the matrix

\footnotetext{
${ }^{33} \mathrm{~A}$ connected graph is said to have the small-world property when his diameter and his level of intransitivity are both relatively low, see Watts and Strogatz (1998). This typically happens for low values of $p$.

${ }^{34}$ Our theoretical results are valid for any variance-covariance matrix $\boldsymbol{\Sigma}$. Here the error terms are i.i.d. and homoscedastic. However, since we use an instrumental variables approach to estimate the parameters, we do not exploit this fact to help identification.
} 
of explanatory variables. The second step consists in estimating a 2SLS using as instruments $\widehat{\mathbf{Z}}=\mathbf{Z}\left(\widehat{\boldsymbol{\alpha}}^{2 S L S}\right)$, with $\mathbf{Z}(\boldsymbol{\alpha})=\left[\begin{array}{llll}\mathbf{1} & \mathbf{x} & \mathbf{g x} & E[\mathbf{g y}(\boldsymbol{\alpha}) \mid \mathbf{x}\end{array}\right]$. From the reduced-form equation, it follows that

$$
E[\mathbf{g y}(\boldsymbol{\alpha}) \mid \mathbf{x}]=\mathbf{g}\left(\mathbf{i}-\alpha_{2} \mathbf{g}\right)^{-1}\left[\alpha_{0} \mathbf{1}+\left(\alpha_{1} \mathbf{i}+\alpha_{3} \mathbf{g}\right) \mathbf{x}\right]
$$

Again, since the model is just identified, we obtain

$$
\widehat{\boldsymbol{\alpha}}^{L E E}=\left(\widehat{\mathbf{Z}}^{\prime} \mathbf{X}\right)^{-1} \widehat{\mathbf{Z}}^{\prime} \mathbf{y}
$$

With homoscedastic and i.i.d. error terms, the estimated variance-covariance matrix of the parameters is

$$
V\left(\widehat{\boldsymbol{\alpha}}^{L E E}\right)=\widehat{s}^{2}\left(\widehat{\mathbf{Z}}^{\prime} \mathbf{X}\right)^{-1} \widehat{\mathbf{Z}}^{\prime} \widehat{\mathbf{Z}}\left(\mathbf{X}^{\prime} \widehat{\mathbf{Z}}^{\prime}\right)^{-1}
$$

where $\widehat{s}^{2}=\frac{1}{n-4} \widehat{\mathbf{u}}^{\prime} \widehat{\mathbf{u}}$ and $\widehat{\mathbf{u}}$ are the residuals from this second step.

\subsection{Results}

Table 1 reports the estimation results for Erdös-Rényi graphs. The probability of link formation, or expected density, $d$, is given in column 1. For each level of density, we pick one graph. We look at 1000 draws for the vectors $\boldsymbol{\epsilon}$ and $\mathbf{x}$. For each draw, we estimate the structural parameters. Columns 3-6 of Table 1 report the average estimates and the average standard errors over the 1000 draws. Estimates of the endogenous and the exogenous effect are respectively shown in columns 5 and 6 .

We find that precision is a decreasing function of density. When the density is smaller or equal to 0.3 , the bias on the estimates of both peer effects is relatively small and the precision is relatively good. As the density of the graph increases, precision worsens. None of the two estimates are significant on average at the $10 \%$ level when the density exceeds 0.5 . As expected, when the density is equal to one (complete graph), the estimation procedure diverges.

The estimation results for small-world graphs are given in Tables 2a-2c. Each of these tables are composed of two panels. To each panel corresponds a specific value of $k$. Within each panel, density is fixed and as one goes down the columns, $p$, hence intransitivity, increases. For each value of $k$ and $p$, we pick one graph. Again, for each graph we report the estimate averages over 1000 draws. 
Results are more complex than for Erdös-Rényi graphs. When density is low ( $k$ small), precision is an increasing function of intransitivity. However, for intermediate to high levels of density, the relationship is U-shaped. For $k=50$, the relationship is plainly non-monotonic. In any case, starting from a situation where peer effects are not identified $(p=0)$, a slight increase in the level of intransitivity holding density constant greatly improves identification. As regards the density, a glance across the tables indicates that for a given level of intransitivity, the precision of the estimates is everywhere a decreasing function of density. Overall, these results confirm the role played by the network's structure on the identification of peer effects.

\section{Conclusion}

In this paper, we characterize the conditions under which endogenous and exogenous social effects are identified in a linear-in-means model with general interaction structure. Our analysis shows that both effects can usually be distinguished with network data, although identification may fail for specific networks. Also, when the model is identified, we show, from Monte Carlo simulations, that characteristics of a network, such as its density and its level of intransitivity, may strongly affect the quality of the estimates of the peer effects. At the empirical level, a few recent papers have already used these network effects to separately estimate endogenous and exogenous effects. ${ }^{35}$ Further empirical work is certainly needed to better understand the feasability of these identification strategies.

Our results suggest that there are high benefits to analyzing network data. On the other hand, collecting comprehensive data on relationships between agents can be very costly. The development of electronic databases has, in some instances, dramatically lowered this cost. Thus, studies on co-authorship networks among scientists are linked to the availability of literature databases (see Newman 2001, Goyal et al. 2006). Sampling the network provides a different way to reduce these costs. This can be done in many ways, e.g., see Rothenberg (1995). It would be interesting to study how our identification results apply in such settings. Can the econometrician still recover endogenous and exogenous effects if he only knows a limited part of the network?

Finally, the problems of correlated effects and the endogeneity of link formation remain central.

\footnotetext{
${ }^{35}$ See Laschever (2005), Lin (2005), and our discussion in the introduction.
} 
Experiments, or natural randomizations, provide one answer. In an experimental context, our results could guide empirical research. For instance, appropriate structures of interactions could be imposed on participants in the lab. With non-experimental data, taking differences between endogenous variables can eliminate certain types of unobserved variables, as done in section 3 . Alternatively, two-stage estimations could be attempted on network data. The likelihood of link formation could be estimated in a first step, and social effects conditional on links formed in a second step. This would require to have some understanding on how relationships emerge, hence could be fruitfully combined with theoretical models of network formation. ${ }^{36}$

\footnotetext{
${ }^{36}$ See Weinberg (2004) and Ioannides and Soetevent (2006) for first steps in this direction.
} 


\section{APPENDIX 1}

\section{Proof of Proposition 1.}

Consider two sets of structural parameters $\left(\alpha_{0}, \alpha_{1}, \alpha_{2}, \alpha_{3}\right)$ and $\left(\alpha_{0}^{\prime}, \alpha_{1}^{\prime}, \alpha_{2}^{\prime}, \alpha_{3}^{\prime}\right)$ leading to the same reduced form. It means that $\alpha_{0}\left(\mathbf{i}-\alpha_{2} \mathbf{g}\right)^{-1} \mathbf{1}=\alpha_{0}^{\prime}\left(\mathbf{i}-\alpha_{2}^{\prime} \mathbf{g}\right)^{-1} \mathbf{1}$ and $\left(\alpha_{1} \mathbf{i}+\alpha_{3} \mathbf{g}\right)\left(\mathbf{i}-\alpha_{2} \mathbf{g}\right)^{-\mathbf{1}}=\left(\alpha_{1}^{\prime} \mathbf{i}+\right.$ $\left.\alpha_{3}^{\prime} \mathbf{g}\right)\left(\mathbf{i}-\alpha_{2}^{\prime} \mathbf{g}\right)^{-1}$. Multiply the second equality by $\left(\mathbf{i}-\alpha_{2} \mathbf{g}\right)\left(\mathbf{i}-\alpha_{2}^{\prime} \mathbf{g}\right)$. Since $\forall \alpha,(\mathbf{i}-\alpha \mathbf{g})^{-1} \mathbf{g}=$ $\mathbf{g}(\mathbf{i}-\alpha \mathbf{g})^{-1}$, this is equivalent to

$$
\left(\alpha_{1}-\alpha_{1}^{\prime}\right) \mathbf{i}+\left(\alpha_{3}-\alpha_{3}^{\prime}+\alpha_{1}^{\prime} \alpha_{2}-\alpha_{1} \alpha_{2}^{\prime}\right) \mathbf{g}+\left(\alpha_{3}^{\prime} \alpha_{2}-\alpha_{3} \alpha_{2}^{\prime}\right) \mathbf{g}^{2}=0
$$

Suppose first that $\mathbf{i}, \mathbf{g}$, and $\mathbf{g}^{2}$ are linearly independent. Then, $\alpha_{1}=\alpha_{1}^{\prime}, \alpha_{3}+\alpha_{1}^{\prime} \alpha_{2}=\alpha_{3}^{\prime}+\alpha_{1} \alpha_{2}^{\prime}$, and $\alpha_{3}^{\prime} \alpha_{2}=\alpha_{3} \alpha_{2}^{\prime}$. Suppose first that $\alpha_{3}^{\prime} \alpha_{2} \neq 0$. There exists $\lambda \neq 0$ such that $\alpha_{2}^{\prime}=\lambda \alpha_{2}, \alpha_{3}^{\prime}=\lambda \alpha_{3}$. Substituting yields $\alpha_{3}^{\prime}+\alpha_{1} \alpha_{2}^{\prime}=\lambda\left(\alpha_{3}+\alpha_{1} \alpha_{2}\right)=\alpha_{3}+\alpha_{1} \alpha_{2}$. Since $\alpha_{3}+\alpha_{1} \alpha_{2} \neq 0, \lambda=1$, hence $\alpha_{2}^{\prime}=\alpha_{2}, \alpha_{3}^{\prime}=\alpha_{3}$. Suppose next that $\alpha_{3}^{\prime} \alpha_{2}=0$. Since $\alpha_{3}+\alpha_{1} \alpha_{2} \neq 0$, we cannot have $\alpha_{2}=\alpha_{3}=0$ or $\alpha_{2}^{\prime}=\alpha_{3}^{\prime}=0$. Thus, either $\alpha_{2}=\alpha_{2}^{\prime}=0$ and by the last equation $\alpha_{3}=\alpha_{3}^{\prime}=0$, or $\alpha_{3}=\alpha_{3}^{\prime}=0$ and by the last equation (and since $\alpha_{1} \neq 0$ because $\alpha_{3}+\alpha_{1} \alpha_{2} \neq 0$ ), $\alpha_{2}=\alpha_{2}^{\prime}=0$. To conclude, observe that $\alpha_{0}\left(\mathbf{i}-\alpha_{2} \mathbf{g}\right)^{-1} \mathbf{1}=\alpha_{0}^{\prime}\left(\mathbf{i}-\alpha_{2} \mathbf{g}\right)^{-1} \mathbf{1}$ implies that $\alpha_{0} \mathbf{1}=\alpha_{0}^{\prime} \mathbf{1}$, hence $\alpha_{0}=\alpha_{0}^{\prime}$.

Next, suppose that $\mathbf{i}, \mathbf{g}$, and $\mathbf{g}^{2}$ are linearly dependent, and that no individual is isolated. The latter property implies that $\mathbf{g} \mathbf{1}=\mathbf{1}$, and $\alpha_{0}\left(\mathbf{i}-\alpha_{2} \mathbf{g}\right)^{-1} \mathbf{1}=\alpha_{0} /\left(1-\alpha_{2}\right) \mathbf{1}$. Three equations only need to be satisfied for $\left(\alpha_{0}, \alpha_{1}, \alpha_{2}, \alpha_{3}\right)$ and $\left(\alpha_{0}^{\prime}, \alpha_{1}^{\prime}, \alpha_{2}^{\prime}, \alpha_{3}^{\prime}\right)$ to yield the same reduced form. Therefore, the model is not identified.

Suppose that there are $K$ characteristics and that parameters $\alpha_{1 k}$ and $\alpha_{3 k}$ are associated with characteristic $k$. Structural parameters $\boldsymbol{\alpha}$ and $\boldsymbol{\alpha}^{\prime}$ lead to the same reduced form iff $\alpha_{0}\left(\mathbf{i}-\alpha_{2} \mathbf{g}\right)^{-1} \mathbf{1}=\alpha_{0}^{\prime}(\mathbf{i}-$ $\left.\alpha_{2}^{\prime} \mathbf{g}\right)^{-1} \mathbf{1}$ and $\forall k,\left(\alpha_{1 k} \mathbf{i}+\alpha_{3 k} \mathbf{g}\right)\left(\mathbf{i}-\alpha_{2} \mathbf{g}\right)^{-\mathbf{1}}=\left(\alpha_{1 k} \mathbf{i}+\alpha_{3 k} \mathbf{g}\right)\left(\mathbf{i}-\alpha_{2}^{\prime} \mathbf{g}\right)^{-1}$. Suppose that for some $k_{0}$, $\alpha_{3 k_{0}}+\alpha_{1 k_{0}} \alpha_{2} \neq 0$. If $\mathbf{i}, \mathbf{g}$, and $\mathbf{g}^{2}$ are linearly independent, by the previous argument $\alpha_{0}=\alpha_{0}^{\prime}$, 
$\alpha_{2}=\alpha_{2}^{\prime}, \alpha_{1 k_{0}}=\alpha_{1 k_{0}}^{\prime}$ and $\alpha_{3 k_{0}}=\alpha_{3 k_{0}}^{\prime}$. Then, for any other $k$, multiplying by $\mathbf{i}-\alpha_{2} \mathbf{g}$ leads to $\alpha_{1 k} \mathbf{i}+\alpha_{3 k} \mathbf{g}=\alpha_{1 k} \mathbf{i}+\alpha_{3 k} \mathbf{g}$ hence $\boldsymbol{\alpha}=\boldsymbol{\alpha}^{\prime}$. If $\mathbf{i}, \mathbf{g}$, and $\mathbf{g}^{2}$ are linearly dependent, we can find $\boldsymbol{\alpha} \neq \boldsymbol{\alpha}^{\prime}$ leading to the same reduced-form.

\section{Proof of Proposition 3.}

Suppose that individuals do not interact in groups, and that the network is transitive. We make use of standard properties of directed graphs, see e.g., Bang-Jensen and Cutin (2000). Say that there is a path between $i$ and $j$ in the network if $g_{i j}>0$ or if there exist $i_{1}, \ldots, i_{l}$ such that $g_{i i_{1}} g_{i_{1} i_{2} \ldots} g_{i_{l} j}>0$. A cycle is a path between $i$ and $i$. A strong component of the network is a maximal set $S$ of individuals such that there is path between any two individuals in $S$. The original network induces an acyclic network on the strong components. Thus, there always exist a strong component $S$ such that $\forall i \in S, N_{i} \subset S$. Transitive directed graphs admit a simple characterization, see Proposition 4.3.1 in Bang-Jensen and Cutin (2000). Especially, their strong components are complete, and the relations between strong components are also complete. Formally, let $S$ and $S^{\prime}$ be two strong components. Then, $\forall i \neq j \in S, g_{i j}>0$. And, if there is a path between $i \in S$ and $i^{\prime} \in S^{\prime}$, then for all $j \in S$ and $j^{\prime} \in S^{\prime}, g_{j j^{\prime}}>0$.

We know that there exists two strong components $S_{1}$ and $S_{2}$ of sizes $s_{1}, s_{2}$ such that: (1) $\forall i \in S_{1}, N_{i}=S_{1}-\{i\}$, and (2) $\forall i \in S_{2}, N_{i}=S \cup S_{2}-\{i\}$ where $S$ is a group size $s \geq s_{1}$ such that $S_{1} \subset S$ and $S_{2} \cap S=\emptyset$. $S_{1}$ is a strong component, which is not affected by any other strong component. $S_{2}$ is a strong component affected by $S_{1}$. We can find $S_{1} \neq S_{2}$ since individuals do not interact in groups. Suppose first that $s_{1}, s_{2} \geq 2$. For any $i \neq j \in S_{1}, g_{i j}=\frac{1}{s_{1}-1}$ while for any $i \neq j \in S_{2}, g_{i j}=\frac{1}{s_{2}+s-1}$. If $\mathbf{g}^{2}=\lambda_{0} \mathbf{i}+\lambda_{1} \mathbf{g}$, then $\forall i,\left(\mathbf{g}^{2}\right)_{i i}=\lambda_{0}$. In addition, $\left(\mathbf{g}^{2}\right)_{i i}=\sum_{j \in N} g_{i j} g_{j i}$. Since $S_{1}$ is a strong component, if $i \in S_{1}$ and $g_{i j} g_{j i}>0$, then $j \in S_{1}$. The same is true for $S_{2}$. Therefore, if $i \in S_{1},\left(\mathbf{g}^{2}\right)_{i i}=\sum_{j \in S_{1}} g_{i j} g_{j i}=\frac{1}{s_{1}-1}$. In contrast, if $i \in S_{2}$, $\left(\mathbf{g}^{2}\right)_{i i}=\sum_{j \in S_{2}} g_{i j} g_{j i}=\frac{s_{2}-1}{\left(s_{2}+s-1\right)^{2}}$. Since $s_{2}+s-1>s_{1}-1$, we have $\frac{s_{2}-1}{\left(s_{2}+s-1\right)^{2}}<\frac{1}{s_{1}-1}$, which is a 
contradiction.

Suppose next that $s_{1}$ or $s_{2}$ is equal to 1 . It means that for some $i,\left(\mathbf{g}^{2}\right)_{i i}=0$. Hence $\lambda_{0}=0$ and for all $i,\left(\mathbf{g}^{2}\right)_{i i}=0$. Therefore, all the strong components of the network have size 1 , and the network is acyclic. In this case, there must exist a pair of individuals $i$ and $j$ such that: (1) $i$ is affected by $j,(2) j$ is isolated, and (3) all the individuals affecting $i$ are isolated. Then, $g_{i j}=\frac{1}{n_{i}}$ and $\left(\mathbf{g}^{2}\right)_{i j}=\sum_{k \in N} g_{i k} g_{k j}=0$. Therefore, $\lambda_{1}=0$, hence $\mathbf{g}^{2}=0$. Therefore, if $\mathbf{g}^{2} \neq 0, \mathbf{i}, \mathbf{g}$, and $\mathbf{g}^{2}$ are linearly independent.

Finally, suppose that $\mathbf{g}^{2}=0$. These networks are characterized by the fact that: (1) no relation is reciprocal, i.e., $j \in N_{i} \Rightarrow i \notin N_{j}$, and (2) they do not have any triad, i.e., sets of three different individuals $i, j, k$ such that $i \in N_{j}$ and $j \in N_{k}$. Two sets of structural coefficients lead to the same reduced form if $\alpha_{1}=\alpha_{1}^{\prime}, \alpha_{3}+\alpha_{1}^{\prime} \alpha_{2}=\alpha_{3}^{\prime}+\alpha_{1} \alpha_{2}^{\prime}$, and $\alpha_{0}\left(\mathbf{i}-\alpha_{2} \mathbf{g}\right)^{-1} \mathbf{1}=\alpha_{0}^{\prime}\left(\mathbf{i}-\alpha_{2}^{\prime} \mathbf{g}\right)^{-1} \mathbf{1}$. The last condition becomes $\alpha_{0} \mathbf{1}-\alpha_{0} \alpha_{2}^{\prime} \mathbf{g} \mathbf{1}=\alpha_{0}^{\prime} \mathbf{1}-\alpha_{0}^{\prime} \alpha_{2} \mathbf{g} \mathbf{1}$. There must exist one isolated and one non-isolated individual in the network. When $i$ is isolated, $(\mathbf{g} 1)_{i}=0$ and $\alpha_{0}=\alpha_{0}^{\prime}$. When $i$ is not isolated, $(\mathbf{g} 1)_{i}=1$, and $\alpha_{0}\left(1-\alpha_{2}^{\prime}\right)=\alpha_{0}^{\prime}\left(1-\alpha_{2}\right)$. Under the assumption that $\alpha_{0} \neq 0$, we have $\alpha_{2}=\alpha_{2}^{\prime}$, hence $\alpha_{3}=\alpha_{3}^{\prime}$ and social effects are identified.

\section{Proof of Proposition 4}

Two sets of structural parameters $\left(\alpha_{1}, \alpha_{2}, \alpha_{3}\right)$ and $\left(\alpha_{1}^{\prime}, \alpha_{2}^{\prime}, \alpha_{3}^{\prime}\right)$ lead to the same reduced form of $(\mathbf{i}-\mathbf{g}) \mathbf{y}$ if and only if $\left(\mathbf{i}-\alpha_{2} \mathbf{g}\right)^{-1}\left(\alpha_{1} \mathbf{i}+\alpha_{3} \mathbf{g}\right)(\mathbf{i}-\mathbf{g})=\left(\mathbf{i}-\alpha_{2}^{\prime} \mathbf{g}\right)^{-1}\left(\alpha_{1}^{\prime} \mathbf{i}+\alpha_{3}^{\prime} \mathbf{g}\right)(\mathbf{i}-\mathbf{g})$. This is equivalent to

$$
\left(\alpha_{1}-\alpha_{1}^{\prime}\right) \mathbf{i}+\left[\alpha_{3}-\alpha_{3}^{\prime}-\left(\alpha_{1}-\alpha_{1}^{\prime}\right)+\alpha_{1}^{\prime} \alpha_{2}-\alpha_{1} \alpha_{2}^{\prime}\right] \mathbf{g}-\left[\alpha_{3}-\alpha_{3}^{\prime}+\alpha_{2}^{\prime}\left(\alpha_{3}-\alpha_{1}\right)-\alpha_{2}\left(\alpha_{3}^{\prime}-\alpha_{1}^{\prime}\right)\right] \mathbf{g}^{2}+\left(\alpha_{2}^{\prime} \alpha_{3}-\alpha_{2} \alpha_{3}^{\prime}\right) \mathbf{g}^{3}=0
$$

Suppose first that $\mathbf{i}, \mathbf{g}, \mathbf{g}^{2}$, and $\mathbf{g}^{3}$ are linearly independent. Then, $\alpha_{1}=\alpha_{1}^{\prime}, \alpha_{3}+\alpha_{1} \alpha_{2}=$ $\alpha_{3}^{\prime}+\alpha_{1} \alpha_{2}^{\prime}$, and $\alpha_{2}^{\prime} \alpha_{3}=\alpha_{2} \alpha_{3}^{\prime}$. By the same argument as in the proof of Proposition $1, \alpha_{2}=\alpha_{2}^{\prime}$ 
and $\alpha_{3}=\alpha_{3}^{\prime}$. Suppose next that $\mathbf{i}, \mathbf{g}, \mathbf{g}^{2}$, and $\mathbf{g}^{3}$ are linearly dependent. If $\mathbf{g}^{2}=\lambda_{0} \mathbf{i}+\lambda_{1} \mathbf{g}$, only two equations must be satisfied for $\left(\alpha_{1}, \alpha_{2}, \alpha_{3}\right)$ and $\left(\alpha_{1}^{\prime}, \alpha_{2}^{\prime}, \alpha_{3}^{\prime}\right)$ to lead to the same reduced form, hence social effects are not identified. If $\mathbf{g}^{3}=\lambda_{0} \mathbf{i}+\lambda_{1} \mathbf{g}+\lambda_{2} \mathbf{g}^{2},\left(\alpha_{1}, \alpha_{2}, \alpha_{3}\right)$ and $\left(\alpha_{1}^{\prime}, \alpha_{2}^{\prime}, \alpha_{3}^{\prime}\right)$ lead to the same reduced form of $(\mathbf{i}-\mathbf{g}) \mathbf{y}$ if and only if the following three equations are satisfied

$$
\begin{aligned}
\alpha_{1}-\alpha_{1}^{\prime}+\lambda_{0}\left(\alpha_{2}^{\prime} \alpha_{3}-\alpha_{2} \alpha_{3}^{\prime}\right) & =0 \\
\alpha_{3}-\alpha_{3}^{\prime}-\left(\alpha_{1}-\alpha_{1}^{\prime}\right)+\alpha_{1}^{\prime} \alpha_{2}-\alpha_{1} \alpha_{2}^{\prime}+\lambda_{1}\left(\alpha_{2}^{\prime} \alpha_{3}-\alpha_{2} \alpha_{3}^{\prime}\right) & =0 \\
-\left(\alpha_{3}-\alpha_{3}^{\prime}\right)-\alpha_{2}^{\prime}\left(\alpha_{3}-\alpha_{1}\right)+\alpha_{2}\left(\alpha_{3}^{\prime}-\alpha_{1}^{\prime}\right)+\lambda_{2}\left(\alpha_{2}^{\prime} \alpha_{3}-\alpha_{2} \alpha_{3}^{\prime}\right) & =0
\end{aligned}
$$

Since no individual is isolated, $\mathbf{g} \mathbf{1}=\mathbf{1}$, and $\lambda_{0}+\lambda_{1}+\lambda_{2}=1$. This means that the third equation can be simply obtained by summing the first two. Hence two equations only need to be satisfied, and social effects are not identified.

With $K$ characteristics, $\boldsymbol{\alpha}$ and $\boldsymbol{\alpha}^{\prime}$ lead to the same reduced-form iff $\forall k,\left(\mathbf{i}-\alpha_{2} \mathbf{g}\right)^{-1}\left(\alpha_{1 k} \mathbf{i}+\right.$ $\left.\alpha_{3 k} \mathbf{g}\right)(\mathbf{i}-\mathbf{g})=\left(\mathbf{i}-\alpha_{2}^{\prime} \mathbf{g}\right)^{-1}\left(\alpha_{1 k}^{\prime} \mathbf{i}+\alpha_{3 k}^{\prime} \mathbf{g}\right)(\mathbf{i}-\mathbf{g})$. Suppose that $\alpha_{3 k_{0}}+\alpha_{1 k_{0}} \alpha_{2} \neq 0$. If $\mathbf{i}, \mathbf{g}, \mathbf{g}^{2}$, and $\mathbf{g}^{3}$ are linearly independent, then $\alpha_{2}=\alpha_{2}^{\prime}, \alpha_{1 k_{0}}=\alpha_{1 k_{0}}^{\prime}$ and $\alpha_{3 k_{0}}=\alpha_{3 k_{0}}^{\prime}$. For any other $k$, multiplying by $\mathbf{i}-\alpha_{2} \mathbf{g}$ leads to $\left(\alpha_{1 k}-\alpha_{1 k}^{\prime}\right) \mathbf{i}+\left(\alpha_{3 k}-\alpha_{3 k}^{\prime}+\alpha_{1 k}^{\prime}-\alpha_{1 k}\right) \mathbf{g}+\left(\alpha_{3 k}^{\prime}-\alpha_{3 k}\right) \mathbf{g}^{2}=0$, hence $\alpha_{1 k}=\alpha_{1 k}^{\prime}$ and $\alpha_{3 k}=\alpha_{3 k}^{\prime}$.

\section{Proof of Proposition 6.}

We first show that social effects are identified if and only if the following condition is true. If $\mu_{0} \mathbf{i}+\mu_{1} \mathbf{g}+\mu_{2} \mathbf{g}^{2}$ has identical rows over each component, then $\mu_{0}=\mu_{1}=\mu_{2}=0$.

Suppose that the condition holds. Consider $c$ one component of $\mathbf{g}$. On $c$, the reduced form of equation (7) can be written $\mathbf{y}=\frac{\mu_{c}}{1-\alpha_{2}} \mathbf{1}_{c}+\left(\mathbf{i}-\alpha_{2} \mathbf{g}\right)^{-1}\left(\alpha_{1} \mathbf{i}+\alpha_{3} \mathbf{g}\right) \mathbf{x}+\boldsymbol{\nu}$. Averaging over the 
component and subtracting yields:

$$
\mathbf{y}-\frac{1}{|c|}\left(\sum_{i=1}^{|c|} y_{i}\right) \mathbf{1}_{c}=\left(\mathbf{i}-\alpha_{2} \mathbf{g}\right)^{-1}\left(\alpha_{1} \mathbf{i}+\alpha_{3} \mathbf{g}\right) \mathbf{x}-\varphi(\mathbf{x}, \boldsymbol{\alpha}) \mathbf{1}+\boldsymbol{\nu}^{\prime}
$$

where $|c|$ is the size of the component, $\boldsymbol{\alpha}=\left(\alpha_{1}, \alpha_{2}, \alpha_{3}\right)$, and $\varphi(\mathbf{x}, \boldsymbol{\alpha})=\frac{1}{|c|} \sum_{j=1}^{|c|}\left[\left(\mathbf{i}-\alpha_{2} \mathbf{g}\right)^{-1}\left(\alpha_{1} \mathbf{i}+\right.\right.$ $\left.\left.\alpha_{3} \mathbf{g}\right) \mathbf{x}\right]_{j}$ is linear in $\mathbf{x}$. Next suppose that $\left(\alpha_{1}, \alpha_{2}, \alpha_{3}\right)$ and $\left(\alpha_{1}^{\prime}, \alpha_{2}^{\prime}, \alpha_{3}^{\prime}\right)$ lead to the same reduced form. It means that $\forall \mathbf{x},\left(\mathbf{i}-\alpha_{2} \mathbf{g}\right)^{-1}\left(\alpha_{1} \mathbf{i}+\alpha_{3} \mathbf{g}\right) \mathbf{x}-\varphi(\mathbf{x}, \boldsymbol{\alpha}) \mathbf{1}=\left(\mathbf{i}-\alpha_{2}^{\prime} \mathbf{g}\right)^{-1}\left(\alpha_{1}^{\prime} \mathbf{i}+\alpha_{3}^{\prime} \mathbf{g}\right) \mathbf{x}-\varphi\left(\mathbf{x}, \boldsymbol{\alpha}^{\prime}\right) \mathbf{1}$. Multiplying by $\mathbf{i}-\alpha_{2} \mathbf{g}$ and $\mathbf{i}-\alpha_{2}^{\prime} \mathbf{g}$ gives $\forall \mathbf{x},\left[\left(\alpha_{1}-\alpha_{1}^{\prime}\right) \mathbf{i}+\left(\alpha_{3}-\alpha_{3}^{\prime}+\alpha_{1}^{\prime} \alpha_{2}-\alpha_{1} \alpha_{2}^{\prime}\right) \mathbf{g}+\left(\alpha_{2}^{\prime} \alpha_{3}-\right.\right.$ $\left.\left.\alpha_{2} \alpha_{3}^{\prime}\right) \mathbf{g}^{2}\right] \mathbf{x}=\left(1-\alpha_{2}\right)\left(1-\alpha_{2}^{\prime}\right)\left[\varphi(\mathbf{x}, \boldsymbol{\alpha})-\varphi\left(\mathbf{x}, \boldsymbol{\alpha}^{\prime}\right)\right] \mathbf{1}$. This means that the matrix $\left(\alpha_{1}-\alpha_{1}^{\prime}\right) \mathbf{i}+\left(\alpha_{3}-\right.$ $\left.\alpha_{3}^{\prime}+\alpha_{1}^{\prime} \alpha_{2}-\alpha_{1} \alpha_{2}^{\prime}\right) \mathbf{g}+\left(\alpha_{2}^{\prime} \alpha_{3}-\alpha_{2} \alpha_{3}^{\prime}\right) \mathbf{g}^{2}$ has identical rows over each component. Thus, $\alpha_{1}=\alpha_{1}^{\prime}$, $\alpha_{3}+\alpha_{1}^{\prime} \alpha_{2}=\alpha_{3}^{\prime}+\alpha_{1} \alpha_{2}^{\prime}$, and $\alpha_{2}^{\prime} \alpha_{3}=\alpha_{2} \alpha_{3}^{\prime}$, and, using the argument in the proof of Prop. 1 , social effects are identified.

Conversely, suppose that the condition does not hold. There exist $\mu_{0}, \mu_{1}, \mu_{2}$ not all equal to zero such that $\mu_{0} \mathbf{i}+\mu_{1} \mathbf{g}+\mu_{2} \mathbf{g}^{2}$ has identical rows over each component. We follow the previous reasoning in reverse. We can find $\boldsymbol{\alpha} \neq \boldsymbol{\alpha}^{\prime}$ such that $\mu_{0}=\alpha_{1}-\alpha_{1}^{\prime}, \mu_{1}=\alpha_{3}-\alpha_{3}^{\prime}+\alpha_{1}^{\prime} \alpha_{2}-\alpha_{1} \alpha_{2}^{\prime}$, and $\mu_{2}=\alpha_{2}^{\prime} \alpha_{3}-\alpha_{2} \alpha_{3}^{\prime}$. Then, $\left(\alpha_{1}-\alpha_{1}^{\prime}\right) \mathbf{i}+\left(\alpha_{3}-\alpha_{3}^{\prime}+\alpha_{1}^{\prime} \alpha_{2}-\alpha_{1} \alpha_{2}^{\prime}\right) \mathbf{g}+\left(\alpha_{2}^{\prime} \alpha_{3}-\alpha_{2} \alpha_{3}^{\prime}\right) \mathbf{g}^{2}$ has identical rows over each component. Over each component $c$, there exists $\left(r_{j}\right)$ such that $\forall \mathbf{x},\left[\left(\alpha_{1}-\alpha_{1}^{\prime}\right) \mathbf{i}+\left(\alpha_{3}-\alpha_{3}^{\prime}+\right.\right.$ $\left.\left.\alpha_{1}^{\prime} \alpha_{2}-\alpha_{1} \alpha_{2}^{\prime}\right) \mathbf{g}+\left(\alpha_{2}^{\prime} \alpha_{3}-\alpha_{2} \alpha_{3}^{\prime}\right) \mathbf{g}^{2}\right] \mathbf{x}=\left(1-\alpha_{2}\right)\left(1-\alpha_{2}^{\prime}\right)\left(\sum_{j=1}^{|c|} r_{j} x_{j}\right) \mathbf{1}$. Dividing by $\mathbf{i}-\alpha_{2} \mathbf{g}$ and $\mathbf{i}-\alpha_{2}^{\prime} \mathbf{g}$ means that $\forall \mathbf{x},\left(\mathbf{i}-\alpha_{2} \mathbf{g}\right)^{-1}\left(\alpha_{1} \mathbf{i}+\alpha_{3} \mathbf{g}\right) \mathbf{x}-\left(\mathbf{i}-\alpha_{2}^{\prime} \mathbf{g}\right)^{-1}\left(\alpha_{1}^{\prime} \mathbf{i}+\alpha_{3}^{\prime} \mathbf{g}\right) \mathbf{x}=\left(\sum_{j=1}^{|c|} r_{j} x_{j}\right) \mathbf{1}$. Averaging over the component yields $\varphi(\mathbf{x}, \boldsymbol{\alpha})-\varphi\left(\mathbf{x}, \boldsymbol{\alpha}^{\prime}\right)=\sum_{j=1}^{|c|} r_{j} x_{j}$. Therefore, $\forall \mathbf{x},\left(\mathbf{i}-\alpha_{2} \mathbf{g}\right)^{-1}\left(\alpha_{1} \mathbf{i}+\alpha_{3} \mathbf{g}\right) \mathbf{x}-$ $\varphi(\mathbf{x}, \boldsymbol{\alpha}) \mathbf{1}=\left(\mathbf{i}-\alpha_{2}^{\prime} \mathbf{g}\right)^{-1}\left(\alpha_{1}^{\prime} \mathbf{i}+\alpha_{3}^{\prime} \mathbf{g}\right) \mathbf{x}-\varphi\left(\mathbf{x}, \boldsymbol{\alpha}^{\prime}\right) \mathbf{1}$. This means that $\boldsymbol{\alpha}$ and $\boldsymbol{\alpha}^{\prime}$ have the same reduced form, hence social effects are not identified.

Next, suppose that $\mu_{0} \mathbf{i}+\mu_{1} \mathbf{g}+\mu_{2} \mathbf{g}^{2}$ has identical rows over each component. Since $\mathbf{g} \mathbf{1}_{c}=\mathbf{1}_{c}$, multiplying by $\mathbf{g}$ leaves the matrix unchanged. Thus, $\mu_{0} \mathbf{i}+\mu_{1} \mathbf{g}+\mu_{2} \mathbf{g}^{2}=\mu_{0} \mathbf{g}+\mu_{1} \mathbf{g}^{2}+\mu_{2} \mathbf{g}^{3}$. If 
$\mathbf{i}, \mathbf{g}, \mathbf{g}^{2}$, and $\mathbf{g}^{3}$ are linearly independent, then $\mu_{0}=\mu_{1}=\mu_{2}=0$, and social effects are identified. If $\mathbf{g}^{3}=\lambda_{0} \mathbf{i}+\lambda_{1} \mathbf{g}+\lambda_{2} \mathbf{g}^{2}$, and $\mu_{2}=0$, then $\mu_{0}=\mu_{1}=0$. If $\mu_{2} \neq 0$, we can set $\mu_{2}=1$. This yields $\mu_{0}=\lambda_{0}$ and $\mu_{1}=\lambda_{0}+\lambda_{1}$. In other words, either $\lambda_{0} \mathbf{i}+\left(\lambda_{0}+\lambda_{1}\right) \mathbf{g}+\mathbf{g}^{2}$ has identical rows over components, and social effects are not identified, or there is one component such that $\lambda_{0} \mathbf{i}+\left(\lambda_{0}+\lambda_{1}\right) \mathbf{g}+\mathbf{g}^{2}$ does not have identical rows, and social effects are identified.

Finally, let $\mathbf{m}=\lambda_{0} \mathbf{i}+\left(\lambda_{0}+\lambda_{1}\right) \mathbf{g}+\mathbf{g}^{2}$. Notice that $\mathbf{g m}=\lambda_{0} \mathbf{g}+\left(\lambda_{0}+\lambda_{1}\right) \mathbf{g}^{2}+\mathbf{g}^{3}=\mathbf{m}$. It means that on any component, any column $\mathbf{m}_{j}$ of $\mathbf{m}$ satisfies $\mathbf{g m}_{j}=\mathbf{m}_{j}$. Suppose that $\operatorname{rank}(\mathbf{i}-\mathbf{g})=n-|C|$. It means that on any component, $\operatorname{dim} \operatorname{Ker}(\mathbf{i}-\mathbf{g})=1$. Therefore, on any component $c$ of size $|c|, \mathbf{m}_{j}=\xi_{j} \mathbf{1}$ and all rows of $\mathbf{m}$ are equal to $\left(\xi_{1}, \ldots, \xi_{n_{C}}\right)$. Thus, social effects are not identified. Conversely, suppose that $\mathbf{m}$ has identical rows over components. Take a component, and a vector $\mathbf{u}$ such that $\mathbf{g u}=\mathbf{u}$ on this component. Then, $\mathbf{m u}=\left(2 \lambda_{0}+\lambda_{1}+1\right) \mathbf{u}$. Since $\mathbf{m}$ has identical rows, $\mathbf{m u}$ has identical elements. As soon as $2 \lambda_{0}+\lambda_{1}+1 \neq 0, u_{i}=u_{j}$ and on this component $\operatorname{dim} \operatorname{Ker}(\mathbf{i}-\mathbf{g})=1$, hence $\operatorname{rank}(\mathbf{i}-\mathbf{g})=n-|C|$.

With $K$ characteristics, $\boldsymbol{\alpha}$ and $\boldsymbol{\alpha}^{\prime}$ lead to the same reduced-form iff $\forall k,(\mathbf{i}-\mathbf{h})\left(\alpha_{1 k} \mathbf{i}+\right.$ $\left.\alpha_{3 k} \mathbf{g}\right)\left(\mathbf{i}-\alpha_{2} \mathbf{g}\right)^{-1}=(\mathbf{i}-\mathbf{h})\left(\alpha_{1 k}^{\prime} \mathbf{i}+\alpha_{3 k}^{\prime} \mathbf{g}\right)\left(\mathbf{i}-\alpha_{2}^{\prime} \mathbf{g}\right)^{-1}$. Suppose that $\alpha_{3 k_{0}}+\alpha_{1 k_{0}} \alpha_{2} \neq 0$. If $\mathbf{g}$ satisfies the condition of Proposition 6, then $\alpha_{2}=\alpha_{2}^{\prime}, \alpha_{1 k_{0}}=\alpha_{1 k_{0}}^{\prime}$ and $\alpha_{3 k_{0}}=\alpha_{3 k_{0}}^{\prime}$. For any other $k$, right multiplying by $\mathbf{i}-\alpha_{2} \mathbf{g}$ leads to $(\mathbf{i}-\mathbf{h})\left(\alpha_{1 k} \mathbf{i}+\alpha_{3 k} \mathbf{g}\right)=(\mathbf{i}-\mathbf{h})\left(\alpha_{1 k}^{\prime} \mathbf{i}+\alpha_{3 k}^{\prime} \mathbf{g}\right)$ hence $\alpha_{1 k}=\alpha_{1 k}^{\prime}$ and $\alpha_{3 k}=\alpha_{3 k}^{\prime}$.

\section{Proof of Proposition 7.}

Denote by $\mathbf{r}(\boldsymbol{\alpha}, \mathbf{g})=\left(\mathbf{i}-\alpha_{2} \mathbf{g}\right)^{-1}\left(\alpha_{1} \mathbf{i}+\alpha_{3} \mathbf{g}\right)$ and by $\mathbf{r}_{i}$ its columns. Social effects are not identified if and only if there exists $\alpha \neq \alpha^{\prime}$ such that $\operatorname{dr}(\boldsymbol{\alpha}, \mathbf{g})=\mathbf{d r}\left(\boldsymbol{\alpha}^{\prime}, \mathbf{g}\right)$ This is equivalent to the fact that for every $i$, the vector $\mathbf{r}_{i}(\boldsymbol{\alpha}, \mathbf{g})-\mathbf{r}_{i}\left(\boldsymbol{\alpha}^{\prime}, \mathbf{g}\right)$ belongs to ker $\mathbf{d}$. Therefore, if $\operatorname{ker} \mathbf{d} \subset \operatorname{ker} \mathbf{d}^{\prime}$ and if social effects are not identified for $\mathbf{d}$, then they are not identified for $\mathbf{d}^{\prime}$. 


\section{APPENDIX 2. Perfect collinearity and identification.}

Result 1. Suppose that $\alpha_{1} \alpha_{2}+\alpha_{3} \neq 0$ and that no individual is isolated. Then,

(1) $\forall \mathbf{x}, E(\mathbf{g y} \mid \mathbf{x})=\lambda_{0} \mathbf{1}+\lambda_{1} \mathbf{x}+\lambda_{2} \mathbf{g x} \Rightarrow \mathbf{g}^{2}=\mu_{0} \mathbf{i}+\mu_{1} \mathbf{g}$.

(2) $\mathbf{g}^{2}=\mu_{0} \mathbf{i}+\mu_{1} \mathbf{g}$ and $\mu_{0} \alpha_{2} \neq-1 \Rightarrow \forall \mathbf{x}, E(\mathbf{g y} \mid \mathbf{x})=\lambda_{0} \mathbf{1}+\lambda_{1} \mathbf{x}+\lambda_{2} \mathbf{g x}$.

Proof. Recall, from 2, that $\mathbf{y}=\frac{\alpha_{0}}{1-\alpha_{2}} \mathbf{1}+\left(\mathbf{i}-\alpha_{2} \mathbf{g}\right)^{-1}\left(\alpha_{1} \mathbf{i}+\alpha_{3} \mathbf{g}\right) \mathbf{x}+\left(\mathbf{i}-\alpha_{2} \mathbf{g}\right)^{-1} \boldsymbol{\epsilon}$. Multiplying by $\mathbf{g}$ and taking the expectation yields:

$$
E(\mathbf{g y} \mid \mathbf{x})=\frac{\alpha_{0}}{1-\alpha_{2}} \mathbf{1}+\left(\mathbf{i}-\alpha_{2} \mathbf{g}\right)^{-1}\left(\alpha_{1} \mathbf{g}+\alpha_{3} \mathbf{g}^{2}\right) \mathbf{x}
$$

One can then see that $\forall \mathbf{x}, E(\mathbf{g y} \mid \mathbf{x})=\lambda_{0} \mathbf{1}+\lambda_{1} \mathbf{x}+\lambda_{2} \mathbf{g x}$ is equivalent to $\lambda_{0}=\frac{\alpha_{0}}{1-\alpha_{2}}$ and

$$
\lambda_{1} \mathbf{i}+\left(\lambda_{2}-\alpha_{2} \lambda_{1}-\alpha_{1}\right) \mathbf{g}-\left(\alpha_{2} \lambda_{2}+\alpha_{3}\right) \mathbf{g}^{2}=0 .
$$

If $\mathbf{i}, \mathbf{g}, \mathbf{g}^{2}$ are linearly independent, then $\lambda_{1}=0, \lambda_{2}=\alpha_{1}$, hence $\alpha_{2} \alpha_{1}+\alpha_{3}=0$, which is not possible. This shows that $\forall \mathbf{x}, E(\mathbf{g y} \mid \mathbf{x})=\lambda_{0} \mathbf{1}+\lambda_{1} \mathbf{x}+\lambda_{2} \mathbf{g x} \Rightarrow \mathbf{g}^{2}=\mu_{0} \mathbf{i}+\mu_{1} \mathbf{g}$.

Reciprocally, suppose that $\mathbf{g}^{2}=\mu_{0} \mathbf{i}+\mu_{1} \mathbf{g}$. We want to find $\lambda_{1}$ and $\lambda_{2}$ such that $\alpha_{2} \lambda_{2}+\alpha_{3} \neq 0$, $\lambda_{1}=\mu_{0}\left(\alpha_{2} \lambda_{2}+\alpha_{3}\right)$ and $\lambda_{2}-\alpha_{2} \lambda_{1}-\alpha_{1}=\mu_{1}\left(\alpha_{2} \lambda_{2}+\alpha_{3}\right)$. This is equivalent to $\lambda_{1}-\mu_{0} \alpha_{2} \lambda_{2}=\mu_{0} \alpha_{3}$ and $\alpha_{2} \lambda_{1}+\left(\mu_{1} \alpha_{2}-1\right) \lambda_{2}=-\alpha_{1}-\mu_{1} \alpha_{3}$. This system has a unique solution in $\lambda_{1}$ and $\lambda_{2}$ if and only if $\mu_{1} \alpha_{2}-1+\mu_{0} \alpha_{2}^{2} \neq 0$. Since $\mathbf{g}^{2} \mathbf{1}=\mathbf{1}, \mu_{0}+\mu_{1}=1$ and the last condition is equivalent to $\mu_{0} \alpha_{2} \neq-1$. If $\mu_{0} \alpha_{2}=-1$, then the system has no solution if $\alpha_{1} \alpha_{2}+\alpha_{3} \neq \alpha_{3}$ and an infinity of solutions otherwise.

With $K$ characteristics, denote by $\mathbf{x}^{k}$ the vector associated with characteristic $k$. We can show through the same reasoning that $\forall \mathbf{x}^{1}, \ldots, \mathbf{x}^{K}, E(\mathbf{g y} \mid \mathbf{x})=\lambda_{0} \mathbf{1}+\sum_{k=1}^{K}\left(\lambda_{1 k} \mathbf{x}^{k}+\lambda_{2 k} \mathbf{g} \mathbf{x}^{k}\right) \Rightarrow \mathbf{g}^{2}=$ $\mu_{0} \mathbf{i}+\mu_{1} \mathbf{g}$ and that $\mathbf{g}^{2}=\mu_{0} \mathbf{i}+\mu_{1} \mathbf{g}$ and $\mu_{0} \alpha_{2} \neq-1 \Rightarrow \forall \mathbf{x}^{1}, \ldots, \mathbf{x}^{K}, E(\mathbf{g y} \mid \mathbf{x})=\lambda_{0} \mathbf{1}+\sum_{k=1}^{K}\left(\lambda_{1 k} \mathbf{x}^{k}+\right.$ 
$\left.\lambda_{2 k} \mathbf{g} \mathbf{x}^{k}\right)$. Observe that here the variables $\left(\mathbf{1}, \mathbf{x}^{1}, \ldots, \mathbf{x}^{K}, \mathbf{g x}^{1}, \ldots, \mathbf{g x}^{K}, \mathbf{g}^{2} \mathbf{x}^{1}, \ldots, \mathbf{g}^{2} \mathbf{x}^{K}, \ldots\right)$ can be used to instrument for gy.

Result 2. Suppose that $\alpha_{1} \alpha_{2}+\alpha_{3} \neq 0$ and that no individual is isolated. Then,

(1) $\forall x, E[(\mathbf{i}-\mathbf{g}) \mathbf{g y} \mid \mathbf{x}]=\lambda_{0}(\mathbf{i}-\mathbf{g}) \mathbf{x}+\lambda_{1}(\mathbf{i}-\mathbf{g}) \mathbf{g x} \Rightarrow \mathbf{g}^{3}=\mu_{0} \mathbf{i}+\mu_{1} \mathbf{g}+\mu_{2} \mathbf{g}^{2}$

(2) $\mathbf{g}^{3}=\mu_{0} \mathbf{i}+\mu_{1} \mathbf{g}+\mu_{2} \mathbf{g}^{2}$ and $\mu_{0} \alpha_{2}\left(1+\alpha_{2}\right)+\mu_{1} \alpha_{2} \neq-1 \Rightarrow \forall x, E[(\mathbf{i}-\mathbf{g}) \mathbf{g y} \mid \mathbf{x}]=\lambda_{0}(\mathbf{i}-\mathbf{g}) \mathbf{x}+$ $\lambda_{1}(\mathbf{i}-\mathbf{g}) \mathbf{g x}$.

Proof. Similarly, $E[(\mathbf{i}-\mathbf{g}) \mathbf{g y} \mid \mathbf{x}]=\left(\mathbf{i}-\alpha_{2} \mathbf{g}\right)^{-1}\left(\alpha_{1} \mathbf{g}+\alpha_{3} \mathbf{g}^{2}\right)(\mathbf{i}-\mathbf{g}) \mathbf{x}$. Therefore, one can see that $\forall \mathbf{x}, E[(\mathbf{i}-\mathbf{g}) \mathbf{g} \mathbf{y} \mid \mathbf{x}]=\lambda_{0}(\mathbf{i}-\mathbf{g}) \mathbf{x}+\lambda_{1}(\mathbf{i}-\mathbf{g}) \mathbf{g x}$ is equivalent to

$$
\lambda_{0} \mathbf{i}+\left(\lambda_{1}-\left(1+\alpha_{2}\right) \lambda_{0}-\alpha_{1}\right) \mathbf{g}+\left(\alpha_{1}-\alpha_{3}-\lambda_{1}-\alpha_{2}\left(\lambda_{1}-\lambda_{0}\right)\right) \mathbf{g}^{2}+\left(\alpha_{2} \lambda_{1}+\alpha_{3}\right) \mathbf{g}^{3}=0 .
$$

If $\mathbf{i}, \mathbf{g}, \mathbf{g}^{2}, \mathbf{g}^{3}$ are linearly independent, then $\lambda_{0}=0, \lambda_{1}=\alpha_{1}$, hence $\alpha_{2} \alpha_{1}+\alpha_{3}=0$, which is not possible.

Reciprocally, suppose that $\mathbf{g}^{3}=\mu_{0} \mathbf{i}+\mu_{1} \mathbf{g}+\mu_{2} \mathbf{g}^{2}$. We want to find $\lambda_{1}$ and $\lambda_{2}$ such that $\alpha_{2} \lambda_{1}+\alpha_{3} \neq 0,-\lambda_{0}=\mu_{0}\left(\alpha_{2} \lambda_{1}+\alpha_{3}\right),-\left(\lambda_{1}-\left(1+\alpha_{2}\right) \lambda_{0}-\alpha_{1}\right)=\mu_{1}\left(\alpha_{2} \lambda_{1}+\alpha_{3}\right)$, and $\left(-\alpha_{1}+\alpha_{3}+\right.$ $\left.\lambda_{1}+\alpha_{2}\left(\lambda_{1}-\lambda_{0}\right)\right)=\mu_{2}\left(\alpha_{2} \lambda_{1}+\alpha_{3}\right)$. Since $\mu_{0}+\mu_{1}+\mu_{2}=1$, one can see that the third equation is a simple linear combination of the first two. Thus, only the first two have to be satisfied. They are equivalent to $\lambda_{0}+\mu_{0} \alpha_{2} \lambda_{1}=-\mu_{0} \alpha_{3}$ and $\left(1+\alpha_{2}\right) \lambda_{0}-\left(1+\mu_{1} \alpha_{2}\right) \lambda_{1}=\mu_{1} \alpha_{3}-\alpha_{1}$. This system as a unique solution if and only if $\mu_{0} \alpha_{2}\left(1+\alpha_{2}\right)+\mu_{1} \alpha_{2} \neq-1$.

As in the previous result, the generalization to $K$ characteristics is straightforward. Here, the variables $\left((\mathbf{i}-\mathbf{g}) \mathbf{x}^{1}, \ldots,(\mathbf{i}-\mathbf{g}) \mathbf{x}^{K},(\mathbf{i}-\mathbf{g}) \mathbf{g x}^{1}, \ldots,(\mathbf{i}-\mathbf{g}) \mathbf{g \mathbf { x } ^ { K }},(\mathbf{i}-\mathbf{g}) \mathbf{g}^{2} \mathbf{x}^{1}, \ldots,(\mathbf{i}-\mathbf{g}) \mathbf{g}^{2} \mathbf{x}^{K}, \ldots\right)$ can be used to instrument for $(\mathbf{i}-\mathbf{g}) \mathbf{g y}$. 
Figure 1: Non directed graphs for which the matrices $\mathrm{i}, \mathrm{g}, \mathrm{g}^{2}$, and $\mathrm{g}^{3}$ are linearly dependent $n=4$

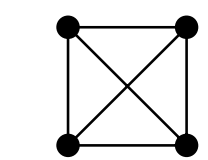

$g^{2}=\frac{1}{3} i+\frac{2}{3} g$

$\mathbf{n}=\mathbf{5}$

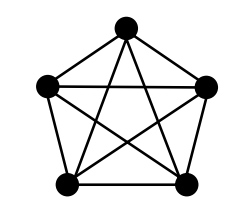

$g^{2}=\frac{1}{4} i+\frac{3}{4} g$

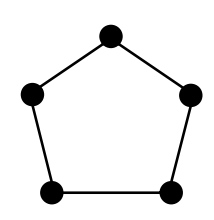

$g^{3}=-\frac{1}{4} i+\frac{3}{4} g+\frac{1}{2} g^{2}$

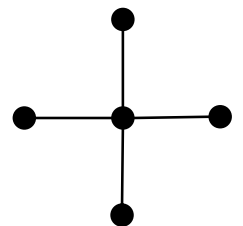

$g^{3}=g$

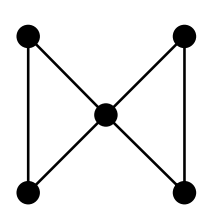

$g^{3}=-\frac{1}{4} i+\frac{1}{4} g+g^{2}$

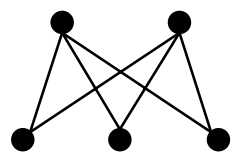

$g^{3}=g$

$\mathbf{n}=\mathbf{6}$

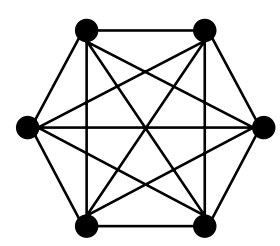

$g^{2}=\frac{1}{5} i+\frac{4}{5} g$

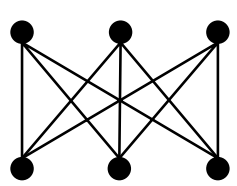

$g^{3}=g$

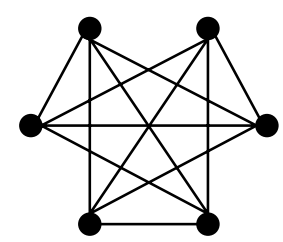

$g^{3}=\frac{1}{2} g+\frac{1}{2} g^{2}$

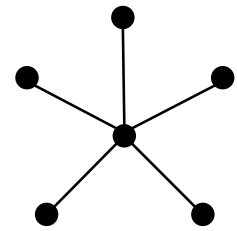

$g^{3}=g$

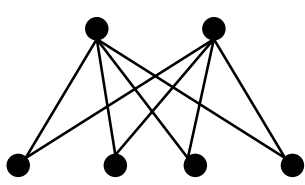

$g^{3}=g$

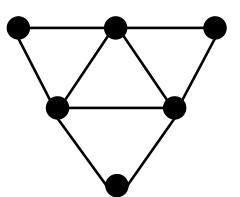

$$
g^{3}=-\frac{1}{8} i+\frac{3}{8} g+\frac{3}{4} g^{2}
$$


Figure 2: A graph for which social effects are identified when using global differences but not when using local differences.

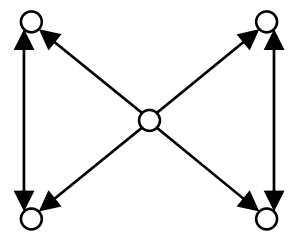


Table 1: Network Simulations for Erdos-Renyi graphs (1000 draws)

\begin{tabular}{|c|c|c|c|c|c|}
\hline Density & Intransitivity & $\begin{array}{c}\hat{\alpha}_{0} \\
\text { (S.E.) }\end{array}$ & $\begin{array}{c}\hat{\alpha}_{1} \\
\text { (S.E.) }\end{array}$ & $\begin{array}{c}\hat{\alpha}_{2} \\
\text { (S.E.) }\end{array}$ & $\begin{array}{c}\hat{\alpha}_{3} \\
\text { (S.E.) }\end{array}$ \\
\hline 0.05 & 0.9477 & $\begin{array}{l}3.0013 \\
1.6816\end{array}$ & $\begin{array}{l}0.7497 \\
0.0071\end{array}$ & $\begin{array}{l}0.5004 \\
0.0269\end{array}$ & $\begin{array}{l}0.6993 \\
0.0237\end{array}$ \\
\hline 0.10 & 0.9005 & $\begin{array}{l}3.0080 \\
4.1868\end{array}$ & $\begin{array}{l}0.7498 \\
0.0071\end{array}$ & $\begin{array}{l}0.4999 \\
0.0686\end{array}$ & $\begin{array}{l}0.6998 \\
0.0549\end{array}$ \\
\hline 0.15 & 0.8469 & $\begin{array}{l}2.7214 \\
6.5377\end{array}$ & $\begin{array}{l}0.7502 \\
0.0070\end{array}$ & $\begin{array}{l}0.5043 \\
0.1080\end{array}$ & $\begin{array}{l}0.6978 \\
0.0838\end{array}$ \\
\hline 0.20 & 0.8093 & $\begin{array}{l}3.5105 \\
9.2527\end{array}$ & $\begin{array}{l}0.7500 \\
0.0071\end{array}$ & $\begin{array}{l}0.4915 \\
0.1527\end{array}$ & $\begin{array}{l}0.7067 \\
0.1158\end{array}$ \\
\hline 0.25 & 0.7507 & $\begin{array}{c}3.3334 \\
12.8648\end{array}$ & $\begin{array}{l}0.7499 \\
0.0071\end{array}$ & $\begin{array}{l}0.4954 \\
0.2121\end{array}$ & $\begin{array}{l}0.7006 \\
0.1593\end{array}$ \\
\hline 0.30 & 0.6990 & $\begin{array}{c}4.2639 \\
17.1369\end{array}$ & $\begin{array}{l}0.7501 \\
0.0071\end{array}$ & $\begin{array}{l}0.4786 \\
0.2838\end{array}$ & $\begin{array}{l}0.7172 \\
0.2116\end{array}$ \\
\hline 0.35 & 0.6403 & $\begin{array}{c}2.0503 \\
22.7531\end{array}$ & $\begin{array}{l}0.7503 \\
0.0071\end{array}$ & $\begin{array}{l}0.5168 \\
0.3762\end{array}$ & $\begin{array}{l}0.6856 \\
0.2789\end{array}$ \\
\hline 0.40 & 0.5927 & $\begin{array}{c}3.5205 \\
27.3555\end{array}$ & $\begin{array}{l}0.7500 \\
0.0070\end{array}$ & $\begin{array}{l}0.4922 \\
0.4537\end{array}$ & $\begin{array}{l}0.7033 \\
0.3353\end{array}$ \\
\hline 0.45 & 0.5413 & $\begin{array}{c}3.7504 \\
33.9050\end{array}$ & $\begin{array}{l}0.7497 \\
0.0071\end{array}$ & $\begin{array}{l}0.4876 \\
0.5605\end{array}$ & $\begin{array}{l}0.7061 \\
0.4131\end{array}$ \\
\hline 0.50 & 0.4989 & $\begin{array}{c}2.2471 \\
40.3953\end{array}$ & $\begin{array}{l}0.7500 \\
0.0071\end{array}$ & $\begin{array}{l}0.5110 \\
0.6696\end{array}$ & $\begin{array}{l}0.6918 \\
0.4924\end{array}$ \\
\hline 0.55 & 0.4441 & $\begin{array}{c}3.0884 \\
51.5507 \\
\end{array}$ & $\begin{array}{l}0.7502 \\
0.0071\end{array}$ & $\begin{array}{l}0.5026 \\
0.8553\end{array}$ & $\begin{array}{l}0.6939 \\
0.6261\end{array}$ \\
\hline 0.60 & 0.3860 & $\begin{array}{c}2.6165 \\
64.5321\end{array}$ & $\begin{array}{l}0.7500 \\
0.0072\end{array}$ & $\begin{array}{l}0.5027 \\
1.0710\end{array}$ & $\begin{array}{l}0.6997 \\
0.7854\end{array}$ \\
\hline 0.65 & 0.3462 & $\begin{array}{c}0.7184 \\
77.8152\end{array}$ & $\begin{array}{l}0.7501 \\
0.0072\end{array}$ & $\begin{array}{l}0.5366 \\
1.2899\end{array}$ & $\begin{array}{l}0.6724 \\
0.9446\end{array}$ \\
\hline 0.70 & 0.3032 & $\begin{array}{l}-1.4445 \\
94.3919\end{array}$ & $\begin{array}{l}0.7503 \\
0.0072\end{array}$ & $\begin{array}{l}0.5762 \\
1.5639\end{array}$ & $\begin{array}{l}0.6446 \\
1.1434\end{array}$ \\
\hline 0.75 & 0.2488 & $\begin{array}{c}-0.7077 \\
122.7888 \\
\end{array}$ & $\begin{array}{l}0.7501 \\
0.0073 \\
\end{array}$ & $\begin{array}{l}0.5683 \\
2.0330 \\
\end{array}$ & $\begin{array}{l}0.6500 \\
1.4854 \\
\end{array}$ \\
\hline 0.80 & 0.2003 & $\begin{array}{c}2.3562 \\
166.9340\end{array}$ & $\begin{array}{l}0.7499 \\
0.0073 \\
\end{array}$ & $\begin{array}{l}0.5069 \\
2.7691\end{array}$ & $\begin{array}{l}0.6903 \\
2.0259\end{array}$ \\
\hline 0.85 & 0.1529 & $\begin{array}{c}-1.9230 \\
237.4791\end{array}$ & $\begin{array}{l}0.7500 \\
0.0075\end{array}$ & $\begin{array}{l}0.5745 \\
3.9225 \\
\end{array}$ & $\begin{array}{l}0.6468 \\
2.8630\end{array}$ \\
\hline 0.90 & 0.0966 & $\begin{array}{c}-57.5221 \\
2072.7681\end{array}$ & $\begin{array}{l}0.7501 \\
0.0125\end{array}$ & $\begin{array}{c}1.4881 \\
33.8434\end{array}$ & $\begin{array}{l}-0.0283 \\
25.1028\end{array}$ \\
\hline 0.95 & 0.0491 & $\begin{array}{c}-49.8582 \\
8637.3878\end{array}$ & $\begin{array}{l}0.7495 \\
0.0206 \\
\end{array}$ & $\begin{array}{c}1.4424 \\
140.1818\end{array}$ & $\begin{array}{c}-0.0308 \\
101.0338 \\
\end{array}$ \\
\hline 1 & 0.000 & $\begin{array}{c}304.8219 \\
->\infty\end{array}$ & $\begin{array}{c}0.8264 \\
->\infty\end{array}$ & $\begin{array}{c}-9.2265 \\
->\infty\end{array}$ & $\begin{array}{c}5.4705 \\
->\infty\end{array}$ \\
\hline
\end{tabular}


Table 2a: Small World graphs, $k=\{4,5\}, 1000$ draws.

\begin{tabular}{|c|c|c|c|c|c|c|}
\hline $\mathrm{k}$ & $\mathrm{p}$ & Intransitivity & $\begin{array}{c}\hat{\alpha}_{0} \\
\text { (S.E.) }\end{array}$ & $\begin{array}{c}\hat{\alpha}_{1} \\
\text { (S.E.) }\end{array}$ & $\begin{array}{c}\hat{\alpha}_{2} \\
\text { (S.E.) }\end{array}$ & $\begin{array}{c}\hat{\alpha}_{3} \\
\text { (S.E.) }\end{array}$ \\
\hline 4 & 0.01 & 0.0396 & $\begin{array}{l}3.0082 \\
0.5249\end{array}$ & $\begin{array}{l}0.7506 \\
0.0295\end{array}$ & $\begin{array}{l}0.4987 \\
0.0476\end{array}$ & $\begin{array}{l}0.7030 \\
0.1073\end{array}$ \\
\hline 4 & 0.05 & 0.1704 & $\begin{array}{l}3.0173 \\
0.4757\end{array}$ & $\begin{array}{l}0.7508 \\
0.0141\end{array}$ & $\begin{array}{l}0.4987 \\
0.0222\end{array}$ & $\begin{array}{l}0.7024 \\
0.0474\end{array}$ \\
\hline 4 & 0.10 & 0.2991 & $\begin{array}{l}3.0202 \\
0.4965\end{array}$ & $\begin{array}{l}0.7500 \\
0.0111\end{array}$ & $\begin{array}{l}0.4993 \\
0.0173\end{array}$ & $\begin{array}{l}0.7014 \\
0.0346\end{array}$ \\
\hline 4 & 0.20 & 0.6395 & $\begin{array}{l}2.9851 \\
0.4462\end{array}$ & $\begin{array}{l}0.7502 \\
0.0077\end{array}$ & $\begin{array}{l}0.5002 \\
0.0093\end{array}$ & $\begin{array}{l}0.6995 \\
0.0176\end{array}$ \\
\hline 4 & 0.40 & 0.8246 & $\begin{array}{l}3.0032 \\
0.4781\end{array}$ & $\begin{array}{l}0.7503 \\
0.0073\end{array}$ & $\begin{array}{l}0.4997 \\
0.0093\end{array}$ & $\begin{array}{l}0.7005 \\
0.0163\end{array}$ \\
\hline 4 & 0.60 & 0.9456 & $\begin{array}{l}2.9855 \\
0.4867\end{array}$ & $\begin{array}{l}0.7502 \\
0.0071\end{array}$ & $\begin{array}{l}0.5000 \\
0.0086\end{array}$ & $\begin{array}{l}0.7005 \\
0.0146\end{array}$ \\
\hline 4 & 0.80 & 0.9652 & $\begin{array}{l}2.9830 \\
0.4644\end{array}$ & $\begin{array}{l}0.7502 \\
0.0070\end{array}$ & $\begin{array}{l}0.5005 \\
0.0081\end{array}$ & $\begin{array}{l}0.6992 \\
0.0137\end{array}$ \\
\hline 4 & 1.00 & 0.9680 & $\begin{array}{l}2.9774 \\
0.4806 \\
\end{array}$ & $\begin{array}{l}0.7502 \\
0.0071\end{array}$ & $\begin{array}{l}0.5004 \\
0.0081 \\
\end{array}$ & $\begin{array}{l}0.6996 \\
0.0135 \\
\end{array}$ \\
\hline 5 & 0.01 & 0.0266 & $\begin{array}{l}3.0019 \\
0.6251\end{array}$ & $\begin{array}{l}0.7509 \\
0.0301\end{array}$ & $\begin{array}{l}0.4979 \\
0.0624\end{array}$ & $\begin{array}{l}0.7055 \\
0.1491\end{array}$ \\
\hline 5 & 0.05 & 0.2096 & $\begin{array}{l}2.9984 \\
0.5676\end{array}$ & $\begin{array}{l}0.7500 \\
0.0116\end{array}$ & $\begin{array}{l}0.5004 \\
0.0230\end{array}$ & $\begin{array}{l}0.6989 \\
0.0498\end{array}$ \\
\hline 5 & 0.10 & 0.3031 & $\begin{array}{l}3.0214 \\
0.5890\end{array}$ & $\begin{array}{l}0.7496 \\
0.0101\end{array}$ & $\begin{array}{l}0.4999 \\
0.0195\end{array}$ & $\begin{array}{l}0.7002 \\
0.0397\end{array}$ \\
\hline 5 & 0.20 & 0.5004 & $\begin{array}{l}3.0008 \\
0.7150\end{array}$ & $\begin{array}{l}0.7498 \\
0.0087\end{array}$ & $\begin{array}{l}0.5002 \\
0.0181\end{array}$ & $\begin{array}{l}0.6995 \\
0.0314\end{array}$ \\
\hline 5 & 0.40 & 0.8288 & $\begin{array}{l}3.0353 \\
0.6558\end{array}$ & $\begin{array}{l}0.7502 \\
0.0071\end{array}$ & $\begin{array}{l}0.4994 \\
0.0119\end{array}$ & $\begin{array}{l}0.7001 \\
0.0182\end{array}$ \\
\hline 5 & 0.60 & 0.9245 & $\begin{array}{l}3.0266 \\
1.2469\end{array}$ & $\begin{array}{l}0.7501 \\
0.0071\end{array}$ & $\begin{array}{l}0.4992 \\
0.0208\end{array}$ & $\begin{array}{l}0.7010 \\
0.0209\end{array}$ \\
\hline 5 & 0.80 & 0.9576 & $\begin{array}{l}2.9818 \\
0.6025\end{array}$ & $\begin{array}{l}0.7498 \\
0.0071\end{array}$ & $\begin{array}{l}0.5003 \\
0.0106\end{array}$ & $\begin{array}{l}0.6998 \\
0.0169\end{array}$ \\
\hline 5 & 1.00 & 0.9584 & $\begin{array}{l}3.0440 \\
0.8009\end{array}$ & $\begin{array}{l}0.7499 \\
0.0070\end{array}$ & $\begin{array}{l}0.4994 \\
0.0132\end{array}$ & $\begin{array}{l}0.7003 \\
0.0174\end{array}$ \\
\hline
\end{tabular}


Table 2b: Small World graphs, $k=\{10,20\}, 1000$ draws.

\begin{tabular}{|c|c|c|c|c|c|c|}
\hline $\mathrm{k}$ & $\mathrm{p}$ & Intransitivity & $\begin{array}{c}\hat{\alpha}_{0} \\
\text { (S.E.) }\end{array}$ & $\begin{array}{c}\hat{\alpha}_{1} \\
\text { (S.E.) }\end{array}$ & $\begin{array}{c}\hat{\alpha}_{2} \\
\text { (S.E.) }\end{array}$ & $\begin{array}{c}\hat{\alpha}_{3} \\
\text { (S.E.) }\end{array}$ \\
\hline 10 & 0.01 & 0.0321 & $\begin{array}{l}3.0077 \\
0.9237 \\
\end{array}$ & $\begin{array}{l}0.7501 \\
0.0188 \\
\end{array}$ & $\begin{array}{l}0.4995 \\
0.0793 \\
\end{array}$ & $\begin{array}{l}0.7015 \\
0.2069 \\
\end{array}$ \\
\hline 10 & 0.05 & 0.1525 & $\begin{array}{l}2.9991 \\
0.9013\end{array}$ & $\begin{array}{l}0.7492 \\
0.0103\end{array}$ & $\begin{array}{l}0.5020 \\
0.0396\end{array}$ & $\begin{array}{l}0.6945 \\
0.0938\end{array}$ \\
\hline 10 & 0.10 & 0.2484 & $\begin{array}{l}3.0294 \\
1.0113\end{array}$ & $\begin{array}{l}0.7495 \\
0.0090\end{array}$ & $\begin{array}{l}0.5015 \\
0.0339\end{array}$ & $\begin{array}{l}0.6947 \\
0.0730\end{array}$ \\
\hline 10 & 0.20 & 0.4743 & $\begin{array}{l}3.1004 \\
1.3026\end{array}$ & $\begin{array}{l}0.7502 \\
0.0079\end{array}$ & $\begin{array}{l}0.4989 \\
0.0311\end{array}$ & $\begin{array}{l}0.6994 \\
0.0529\end{array}$ \\
\hline 10 & 0.40 & 0.7528 & $\begin{array}{l}3.0963 \\
2.1654\end{array}$ & $\begin{array}{l}0.7501 \\
0.0074\end{array}$ & $\begin{array}{l}0.4981 \\
0.0403\end{array}$ & $\begin{array}{l}0.7021 \\
0.0465\end{array}$ \\
\hline 10 & 0.60 & 0.8672 & $\begin{array}{l}2.8426 \\
3.1458 \\
\end{array}$ & $\begin{array}{l}0.7500 \\
0.0071\end{array}$ & $\begin{array}{l}0.5024 \\
0.0536 \\
\end{array}$ & $\begin{array}{l}0.6985 \\
0.0481 \\
\end{array}$ \\
\hline 10 & 0.80 & 0.9086 & $\begin{array}{l}3.1253 \\
3.5709\end{array}$ & $\begin{array}{l}0.7500 \\
0.0071\end{array}$ & $\begin{array}{l}0.4990 \\
0.0586\end{array}$ & $\begin{array}{l}0.6985 \\
0.0480\end{array}$ \\
\hline 10 & 1.00 & 0.9099 & $\begin{array}{l}2.8883 \\
3.6729 \\
\end{array}$ & $\begin{array}{l}0.7502 \\
0.0070 \\
\end{array}$ & $\begin{array}{l}0.5014 \\
0.0600 \\
\end{array}$ & $\begin{array}{l}0.6995 \\
0.0485 \\
\end{array}$ \\
\hline 20 & 0.01 & 0.0339 & $\begin{array}{l}3.0338 \\
1.4941 \\
\end{array}$ & $\begin{array}{l}0.7496 \\
0.0130 \\
\end{array}$ & $\begin{array}{l}0.5009 \\
0.1054 \\
\end{array}$ & $\begin{array}{l}0.6959 \\
0.2818 \\
\end{array}$ \\
\hline 20 & 0.05 & 0.1518 & $\begin{array}{l}3.0723 \\
1.5786\end{array}$ & $\begin{array}{l}0.7499 \\
0.0087\end{array}$ & $\begin{array}{l}0.4989 \\
0.0587\end{array}$ & $\begin{array}{l}0.7007 \\
0.1368\end{array}$ \\
\hline 20 & 0.10 & 0.2678 & $\begin{array}{l}2.9678 \\
1.8760\end{array}$ & $\begin{array}{l}0.7499 \\
0.0079\end{array}$ & $\begin{array}{l}0.5005 \\
0.0522\end{array}$ & $\begin{array}{l}0.6999 \\
0.1040\end{array}$ \\
\hline 20 & 0.20 & 0.4578 & $\begin{array}{l}3.1922 \\
2.7157\end{array}$ & $\begin{array}{l}0.7503 \\
0.0074\end{array}$ & $\begin{array}{l}0.4967 \\
0.0576\end{array}$ & $\begin{array}{l}0.7026 \\
0.0854\end{array}$ \\
\hline 20 & 0.40 & 0.6748 & $\begin{array}{l}3.3740 \\
4.7499\end{array}$ & $\begin{array}{l}0.7497 \\
0.0073\end{array}$ & $\begin{array}{l}0.4944 \\
0.0854\end{array}$ & $\begin{array}{l}0.7028 \\
0.0871\end{array}$ \\
\hline 20 & 0.60 & 0.7760 & $\begin{array}{l}3.0040 \\
7.6492 \\
\end{array}$ & $\begin{array}{l}0.7500 \\
0.0071\end{array}$ & $\begin{array}{l}0.5002 \\
0.1290\end{array}$ & $\begin{array}{l}0.6995 \\
0.1059 \\
\end{array}$ \\
\hline 20 & 0.80 & 0.8044 & $\begin{array}{l}3.1250 \\
8.9864\end{array}$ & $\begin{array}{l}0.7498 \\
0.0070\end{array}$ & $\begin{array}{l}0.4975 \\
0.1486\end{array}$ & $\begin{array}{l}0.7023 \\
0.1142\end{array}$ \\
\hline 20 & 1.00 & 0.8084 & $\begin{array}{l}2.9218 \\
9.3405\end{array}$ & $\begin{array}{l}0.7497 \\
0.0071 \\
\end{array}$ & $\begin{array}{l}0.5018 \\
0.1544\end{array}$ & $\begin{array}{l}0.6969 \\
0.1175\end{array}$ \\
\hline
\end{tabular}


Table 2c: Small World graphs, $k=\{25,50\}, 1000$ draws.

\begin{tabular}{|c|c|c|c|c|c|c|}
\hline $\mathrm{k}$ & $\mathrm{p}$ & Intransitivity & $\begin{array}{c}\hat{\alpha}_{0} \\
\text { (S.E.) }\end{array}$ & $\begin{array}{c}\hat{\alpha}_{1} \\
\text { (S.E.) }\end{array}$ & $\begin{array}{c}\hat{\alpha}_{2} \\
\text { (S.E.) }\end{array}$ & $\begin{array}{c}\hat{\alpha}_{3} \\
\text { (S.E.) }\end{array}$ \\
\hline 25 & 0.01 & 0.0217 & $\begin{array}{l}3.1217 \\
1.9620\end{array}$ & $\begin{array}{l}0.7500 \\
0.0143\end{array}$ & $\begin{array}{l}0.4964 \\
0.1484\end{array}$ & $\begin{array}{l}0.7065 \\
0.4028\end{array}$ \\
\hline 25 & 0.05 & 0.1262 & $\begin{array}{l}3.0693 \\
2.0250\end{array}$ & $\begin{array}{l}0.7502 \\
0.0085\end{array}$ & $\begin{array}{l}0.5002 \\
0.0717\end{array}$ & $\begin{array}{l}0.6965 \\
0.1653\end{array}$ \\
\hline 25 & 0.10 & 0.2770 & $\begin{array}{l}3.0468 \\
2.4580\end{array}$ & $\begin{array}{l}0.7500 \\
0.0077\end{array}$ & $\begin{array}{l}0.5000 \\
0.0628\end{array}$ & $\begin{array}{l}0.6979 \\
0.1170\end{array}$ \\
\hline 25 & 0.20 & 0.4260 & $\begin{array}{l}3.0929 \\
3.3078\end{array}$ & $\begin{array}{l}0.7500 \\
0.0074\end{array}$ & $\begin{array}{l}0.4988 \\
0.0695\end{array}$ & $\begin{array}{l}0.7004 \\
0.1012\end{array}$ \\
\hline 25 & 0.40 & 0.6525 & $\begin{array}{l}3.6216 \\
6.6105 \\
\end{array}$ & $\begin{array}{l}0.7500 \\
0.0072\end{array}$ & $\begin{array}{l}0.4897 \\
0.1163\end{array}$ & $\begin{array}{l}0.7066 \\
0.1105 \\
\end{array}$ \\
\hline 25 & 0.60 & 0.7348 & $\begin{array}{c}2.6441 \\
10.6845 \\
\end{array}$ & $\begin{array}{l}0.7499 \\
0.0071 \\
\end{array}$ & $\begin{array}{l}0.5060 \\
0.1792 \\
\end{array}$ & $\begin{array}{l}0.6949 \\
0.1423 \\
\end{array}$ \\
\hline 25 & 0.80 & 0.7556 & $\begin{array}{c}2.7247 \\
12.4027\end{array}$ & $\begin{array}{l}0.7502 \\
0.0071\end{array}$ & $\begin{array}{l}0.5046 \\
0.2055\end{array}$ & $\begin{array}{l}0.6960 \\
0.1554\end{array}$ \\
\hline 25 & 1.00 & 0.7588 & $\begin{array}{c}2.8411 \\
12.5097 \\
\end{array}$ & $\begin{array}{l}0.7504 \\
0.0071 \\
\end{array}$ & $\begin{array}{l}0.5022 \\
0.2066 \\
\end{array}$ & $\begin{array}{l}0.6998 \\
0.1553 \\
\end{array}$ \\
\hline 50 & 0.01 & 0.0335 & $\begin{array}{c}3.8310 \\
11.3662 \\
\end{array}$ & $\begin{array}{l}0.7495 \\
0.0097 \\
\end{array}$ & $\begin{array}{l}0.4946 \\
0.2885 \\
\end{array}$ & $\begin{array}{l}0.6845 \\
0.5146 \\
\end{array}$ \\
\hline 50 & 0.05 & 0.1280 & $\begin{array}{c}3.3371 \\
10.9162\end{array}$ & $\begin{array}{l}0.7501 \\
0.0078\end{array}$ & $\begin{array}{l}0.4900 \\
0.2225\end{array}$ & $\begin{array}{l}0.7196 \\
0.3027\end{array}$ \\
\hline 50 & 0.10 & 0.2403 & $\begin{array}{c}2.9446 \\
32.4395\end{array}$ & $\begin{array}{l}0.7501 \\
0.0076\end{array}$ & $\begin{array}{l}0.4995 \\
0.5588\end{array}$ & $\begin{array}{l}0.7022 \\
0.4834\end{array}$ \\
\hline 50 & 0.20 & 0.3505 & $\begin{array}{c}4.4018 \\
18.3516 \\
\end{array}$ & $\begin{array}{l}0.7504 \\
0.0072 \\
\end{array}$ & $\begin{array}{l}0.4757 \\
0.3201 \\
\end{array}$ & $\begin{array}{l}0.7172 \\
0.2912 \\
\end{array}$ \\
\hline 50 & 0.40 & 0.4711 & $\begin{array}{c}4.0322 \\
25.7533\end{array}$ & $\begin{array}{l}0.7498 \\
0.0071\end{array}$ & $\begin{array}{l}0.4844 \\
0.4335\end{array}$ & $\begin{array}{l}0.7083 \\
0.3435\end{array}$ \\
\hline 50 & 0.60 & 0.4997 & $\begin{array}{c}4.6724 \\
34.6307\end{array}$ & $\begin{array}{l}0.7501 \\
0.0071\end{array}$ & $\begin{array}{l}0.4724 \\
0.5769\end{array}$ & $\begin{array}{l}0.7207 \\
0.4338\end{array}$ \\
\hline 50 & 0.80 & 0.5014 & $\begin{array}{c}0.8452 \\
39.1768\end{array}$ & $\begin{array}{l}0.7499 \\
0.0071\end{array}$ & $\begin{array}{l}0.5353 \\
0.6509\end{array}$ & $\begin{array}{l}0.6724 \\
0.4816 \\
\end{array}$ \\
\hline 50 & 1.00 & 0.5052 & $\begin{array}{c}3.2033 \\
38.8392 \\
\end{array}$ & $\begin{array}{l}0.7500 \\
0.0071\end{array}$ & $\begin{array}{l}0.4987 \\
0.6428\end{array}$ & $\begin{array}{l}0.6984 \\
0.4737\end{array}$ \\
\hline
\end{tabular}




\section{REFERENCES}

Anselin, L., Florax R. and Rey S. (eds.) (2004): Advances in Spatial econometrics, Methodology, Tools and Applications. Heidelberg: Springer-Verlag.

Bang-Jensen, J., and Cutin, G. (2000): Digraphs: Theory, Algorithms and Applications. London: Springer Monographs in Mathematics.

Blume, L. and Durlauf, S. (2005): "Identifying Social Interactions: A Review", Mimeo, University of Wisconsin.

Brock, W. and Durlauf, S. (2001a): "Discrete Choice with Social Interactions", Review of Economic Studies, 235-260.

Brock, W. and Durlauf, S. (2001b): "Interaction-based Models", Handbook of Econometrics, vol 5, J. Heckman and Leamer E. (Eds), Amstersam: North-Holland.

Brock, W. and Durlauf, S. (2003): "Multinomial Choice with Social Interactions". SSRI Working Paper No. 2003-1, University of Wisconsin.

Calvó-Armengol, A., Patacchini, E., and Zenou, Y. (2005): "Peer Effects and Social Networks in Education", Mimeo, Universitat Autonoma de Barcelona.

Case, A. (1991): "Spatial Patterns in Household Demand", Econometrica, 953-965.

Cliff, A. and Ord J. K. (1981): Spatial Processes. London: Pion.

Conley, T. and Udry, C. (2005): "Learning about a New Technology: Pineapple in Ghana," Mimeo, Yale University.

Davezies, L., d'Haultfoeuille, X. and Fougère, D. (2006): "Identification of Peer Effects Using Group Size Variation", Discussion Paper No. 2324, IZA.

Dercon, S. and De Weerdt, J. (2005): "Risk-Sharing Networks and Insurance against Illness", Forthcoming, Journal of Development Economics.

Evans, W., Oates, W. and Schwab, R. (1992): "Measuring Peer Group Effects: a Study of Teenage Behavior", Journal of Political Economy, 966-991.

Erdös, P and Rényi, A. (1959): "On Random Graphs", Publicationes Mathematicae, 6, 290297.

Fortin, B., Lacroix, G. and Villeval, M.C. (2006): "Tax Evasion and Social Interactions", mimeo, Cirpée, Université Laval.

Gaviria, A. and Raphael, S. (2001): "School based Peer Effects and Juvenile Behavior", Review of Economics and Statistics.

Graham, B. S. and Hahn, J. (2005): "Indentification and Estimation of the Linear-in-Means model of Social Interactions", Economics Letters, 1-6. 
Glaeser, E., Sacerdote, B. and Scheinkman, J. (1996): "Crime and Social Interaction", Quarterly Journal of Economics, 507-548.

Goyal, S., van der Leij, M., and Moraga-Gonzalez, J. L. (2006): "Economics: an Emerging Small World", Journal of Political Economy, 403-412.

Hanushek, E., Kain, J., Markman, J. and Rivkin, S. (2003): "Does Peer Ability Affect Student Achievement?", Journal of Applied Econometrics, 527-544.

Horn, R.A. and Johnson, C.R. (1985): Matrix Analysis. Cambridge: Cambridge Univ. Press.

Ioannides, Yannis and Soetevent A. (2006): "Social Networking and Individual Outcomes beyond the Mean Field Case", Journal of Economic Behavior and Organization, forthcoming.

Kelejian H.H. and Prucha I.R. (1998): "A Generalized Spatial Two-Stage Least Squares Procedure for Estimating a Spatial Autoregressive Model with Autoregressive Disturbances", Journal of Real Estate Finance and Economics, Vol 17, 99-121.

Krauth B. (2006): "Simulation-Based Estimation of Peer Effects ", Journal of Econometrics, Vol 133, 243-271.

Jackson, M. (2006): "The Economics of Social Networks", in Proceedings of the 9th World Congress of the Econometric Society, Vol.1, Cambridge: Cambridge University Press.

Laschever, R. (2005): "The Doughboys Network: Social Interactions and Labor Market Outcomes of World War I Veterans", Mimeo, Northwestern University.

Lee, L. F. (2003): "Best Spatial Two-Stage Least Squares Estimators for a Spatial Autoregressive Model with Autoregressive Disturbances", Econometric Reviews, Vol. 22, No. 4, 307-335.

Lee, L. F . (2006): "Identification and Estimation of Econometric Models with Group Interactions, Contextual Factors and Fixed Effects", Journal of Econometrics, forthcoming.

Lin, X. (2005): "Peer Effects and Student Academic Achievement: an Application of Spatial Autoregressive Model with Group Unobservables", Mimeo, Ohio State University.

Manski, C. (1993): "Identification of Endogenous Social Effects: The Reflection Problem", Review of Economic Studies, 531-542.

Manski, C. (1995): Identification Problems in the Social Sciences. Cambridge, Harvard Univ. Press.

Moffitt, R. (2001): "Policy Interventions, Low-Level Equilibria, and Social Interactions", in Social Dynamics, edited by Steven Durlauf and Peyton Young, MIT press.

Newman, M. (2001): "The structure of scientific collaborations", Proceedings of the National Academy of Science USA, 404-409.

Rothenberg, R. (1995): "Commentary: Sampling in Social Networks", Connections, 104-110. 
Sacerdote, B. (2001): "Peer Effects with Random Assignment: Results for Darmouth Rommmates", Quarterly Journal of Economics, 681-704.

Soetevent, A. (2006): "Empirics of the Identification of Social Interactions: An Evaluation of the Approaches and their Results", Journal of Economic Surveys, 193-228.

Soetevent, A. and Kooreman P. (2006): "A Discrete Choice Model with Social Interactions; with an Application to High School Teen Behavior", Forthcoming, Journal of Applied Econometrics.

Wasserman S. and Faust, K. (1994): Social Network Analysis: Methods and Applications. Cambridge University Press.

Watts, D.J. and Strogatz S.H. (1998), "Collective Dynamics of Small-World Networks", Nature, 393, 440-442.

Zimmerman, D. (2003): "Peer Effects in Academic Outcomes: Evidence from a Natural Experiment", Review of Economics and Statistics, 9-23.

Weinberg, B. (2004): "Social Interactions and Endogenous Associations," Mimeo, Ohio State University. 